OPEN ACCESS

Edited by: Brian T. Fife,

University of Minnesota, United States

Reviewed by: Yukihiro Fujita,

Asahikawa Medical University, Japan

Brian M. Shewchuk,

The Brody School of Medicine at

East Carolina University,

United States

${ }^{*}$ Correspondence: Todd M. Brusko tbrusko@ufl.edu

Specialty section: This article was submitted to

Diabetes,

a section of the journal

Frontiers in Endocrinology

Received: 28 July 2017 Accepted: 02 October 2017 Published: 18 October 2017

Citation:

Wallet MA, Santostefano KE Terada N and Brusko TM (2017) Isogenic Cellular Systems Model the Impact of Genetic Risk Variants in the Pathogenesis of Type 1 Diabetes.

Front. Endocrinol. 8:276. doi: 10.3389/fendo.2017.00276

\section{Isogenic Cellular Systems Model the Impact of Genetic Risk Variants in the Pathogenesis of Type 1 Diabetes}

\author{
Mark A. Wallet, Katherine E. Santostefano, Naohiro Terada and Todd M. Brusko* \\ Department of Pathology, Immunology, and Laboratory Medicine, University of Florida Diabetes Institute, College of \\ Medicine, Gainesville, FL, United States
}

At least 57 independent loci within the human genome confer varying degrees of risk for the development of type 1 diabetes (T1D). The majority of these variants are thought to contribute to overall genetic risk by modulating host innate and adaptive immune responses, ultimately resulting in a loss of immunological tolerance to $\beta$ cell antigens. Early efforts to link specific risk variants with functional alterations in host immune responses have employed animal models or genotype-selected individuals from clinical bioresource banks. While some notable genotype:phenotype associations have been described, there remains an urgent need to accelerate the discovery of causal variants and elucidate the molecular mechanisms by which susceptible alleles alter immune functions. One significant limitation has been the inability to study human T1D risk loci on an isogenic background. The advent of induced pluripotent stem cells (iPSCs) and genome-editing technologies have made it possible to address a number of these outstanding questions. Specifically, the ability to drive multiple cell fates from iPSC under isogenic conditions now facilitates the analysis of causal variants in multiple cellular lineages. Bioinformatic analyses have revealed that T1D risk genes cluster within a limited number of immune signaling pathways, yet the relevant immune cell subsets and cellular activation states in which candidate risk genes impact cellular activities remain largely unknown. In this review, we summarize the functional impact of several candidate risk variants on host immunity in T1D and present an isogenic disease-in-a-dish model system for interrogating risk variants, with the goal of expediting precision therapeutics in T1D.

\footnotetext{
Keywords: type 1 diabetes, autoimmunity, induced pluripotent stem cells, gene editing, genome-wide association studies, expression quantitative trait loci
}

\section{INTRODUCTION}

The combined genetic and environmental factors that result in type 1 diabetes (T1D) are reflected in the heterogeneous clinical presentations of the disease (1). This autoimmune process results from a complex cross-talk between cells of the innate and adaptive arms of the immune system and the target $\beta$ cells within the islet microenvironment (Figure 1) (2). The era of genome-wide association studies (GWAS) has heralded discovery of approximately 57 independent loci conferring some component to the overall genetic risk for the development of T1D (3). This vast discovery effort has reinforced prior notions of an autoimmune basis for disease development and also has shed new light on the 


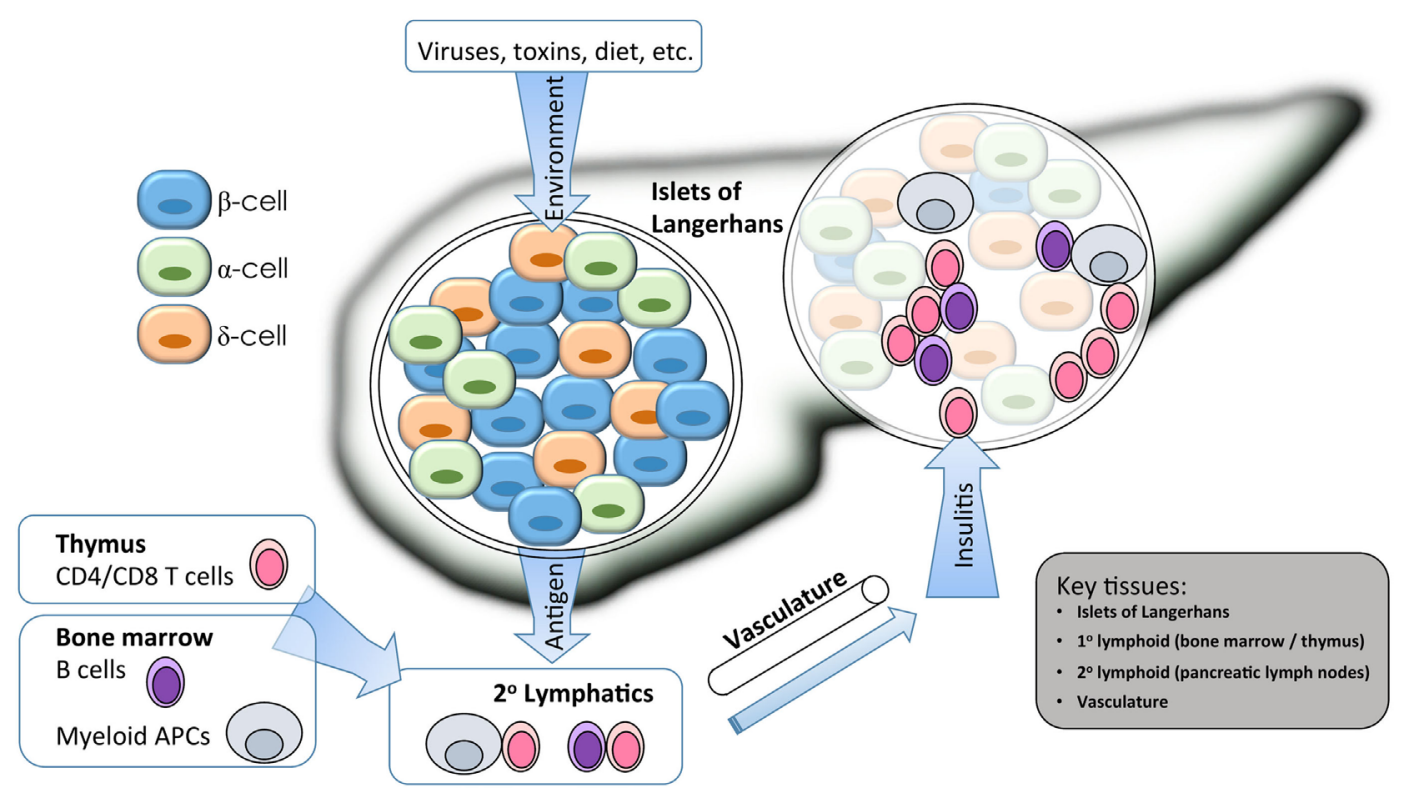

FIGURE 1 | Isogenic modeling facilitates the investigation of multiple cell types important in the pathogenesis of type 1 diabetes (T1D). A combination of environmental and genetic factors influences the overall risk for T1D. Genes conferring risk for T1D may affect the functions of $\beta$ cells, immune cells, and vascular endothelium. For $\beta$ cells, risk variants of some genes may alter the response to environmental triggers such as inflammatory or viral sensing, or they may alter the way that $\beta$ cells cope with stress from bioenergetic demands. For immune cells, gene variants my alter the way that $\mathrm{T}$ and $\mathrm{B}$ cells are selected in primary $\left(1^{\circ}\right.$ ) lymphatic tissues during central tolerance, or they may alter several key events that occur during antigen-specific priming and effector differentiation in the peripheral $\left(2^{\circ}\right)$ lymphatics. Immune destruction of $\beta$ cells requires homing of innate and adaptive effector populations into the pancreatic islets, so alterations to endothelial function could affect disease at this late stage. Isogenic cellular modeling can be applied to complex multifactorial diseases to facilitate a more complete understanding of which genes are expressed in any given tissue/cell type and at which developmental stage they may exert their influence on disease progression.

etiology of T1D, including support for cellular stress within $\beta$ cells contributing to their demise (4). Despite these advances, there remain numerous questions regarding the mechanisms by which causal gene variants, both individually and in concert, impact immune checkpoints and $\beta$ cell responses throughout the natural history of the disease. Thus, there remains a critical need in the field to address some fundamental questions regarding the single-nucleotide polymorphisms (SNPs) identified by GWAS including (1) What are the causative variants within any given tag SNP locus? (2) In what cell type(s) and developmental stage(s) are the candidate genes actively expressed? (3) What environmental stimuli modify candidate gene expression or activity? And ultimately, (4) what variants and/or pathways are amenable to therapeutic interventions?

A number of large-scale mechanistic studies to discern the impact of specific genotypes on resulting phenotypes are underway from population-based studies (5). These investigations often utilize clinical material derived from bioresource banks (i.e., genotyped clinical samples capable of recall or recovery from cryopreservation) (6). While promising results have emerged, the number of well-characterized genotype:phenotype interactions remains limited to a small fraction of the putatively identified risk loci. The paucity of functional studies validating causative SNPs can be attributed to a number of challenges including the need to acquire sufficient clinical blood volumes for functional testing, limited access to biological replicates to account for human heterogeneity (particularly with low minor allele frequency variants), and the clear potential for epistatic genetic influences. In sum, these confounding factors constitute a considerable discovery bottleneck limiting human studies by the larger research community.

Immunodeficient mouse models, so-called "humanized" mice, capable of being engrafted with primary human lymphocytes or hematopoietic stem cells (HSCs) have been proposed as a means to fill the translational gap between in vitro human studies and clinical trials. These rodent models display full organism level complexity yet can still be manipulated experimentally (7). Despite the powerful tool humanized mice provide when used appropriately, they still present significant constraints as a model system. Mice hold notable differences when compared to human biology, particularly when considering host immune responses in the context of TLR ligands, responses to cytokines and growth factors, and cellular trafficking (8). These factors present challenges in modeling autoimmune T1D in xenogeneic systems, where there are essential homology requirements for full effector function. These requirements include the need for lymphocyte trafficking from circulation to secondary lymphoid organs, auto-antigen priming and activation, and eventual extravasation to target $\beta$ cells within islets (9). The emergence of induced pluripotent stem cell (iPSC) technologies offers an attractive alternative to humanized mice that allows the interrogation of underlying genetic defects using a vast array of relevant biological tissues and cell types avoiding both allo- and xenogeneic responses. 
Isogenic cellular systems constitute a powerful experimental platform for conducting precision gene editing to create a "disease-in-a-dish" model to interrogate multifactorial diseases such as T1D. This methodology provides an opportunity to understand specific molecular mechanisms and pathways in humans to thereby derive rational therapeutics using a precision medicine approach. In this review, we describe some of the emerging technologies for generating and manipulating iPSC-derived cells and tissues to interrogate causative genes and pathways in T1D.

\section{ISOGENIC CELLULAR SYSTEMS}

Investigations into the etiopathogenesis of T1D have historically been dominated by studies of peripheral blood. Over the last decade, the Network for Pancreatic Organ donors with Diabetes (nPOD) program has provided essential access to the pancreas and lymphoid tissues from donors with T1D. Emerging studies from this program have already challenged many of the preconceived notions of the disease. Of note, nPOD tissues have highlighted disease heterogeneity across T1D donors and remarkable variability even at the level of adjacent islets within a single T1D donor (10-14). For example, early histological observations from nPOD led Dr. George Eisenbarth to refer to T1D as "vitiligo of the pancreas," in reference to intact insulin-containing islets being observed in close proximity to pseudo-atrophic islets completely devoid of insulin (15). Despite the transformative resource that $n P O D$ provides, donor and programmatic limitations necessitate systematic prioritization of access to tissues. Hence, there is a paramount need within the field to derive cell types from renewable human cellular sources. The capacity for pluripotent and renewable cells to undergo reprogramming to generate immune subsets, endothelial cells, and neuroendocrine lineages will facilitate the modeling of cellular interactions involved in T1D disease pathogenesis (Figure 2).

\section{GENETIC SUSCEPTIBILITY IN T1D}

The autoimmune destruction of insulin-producing pancreatic $\beta$ cells in T1D shares complex etiology with a collection of organspecific disorders (i.e., juvenile idiopathic arthritis, alopecia areata, rheumatoid arthritis, and celiac disease, among others) (3). Though each of these diseases demonstrates unique immunopathologic mechanisms, they all share two common features: specifically, inheritance with a significant genetic contribution coming from the human leukocyte antigen (HLA) region of chromosome 6 and additional genetic risk conferred by loci dispersed throughout the genome (Table 1). While no single risk haplotype accurately predicts whether or not a person will develop T1D (or another autoimmune disease), there is clear genetic evidence that T1D is primarily an inherited disease with an autoimmune pathogenesis (Figure 3) and with additional poorly defined environmental contributions. Discordant incidence of T1D in monozygotic twins is often cited as evidence for a greater environmental role in T1D $(16,17)$; however, the early studies likely underestimated the concordance rates. It is now better understood that childhood-onset T1D and latent autoimmune diabetes of the adult (LADA) share overlapping genetic risk (18). Thus, long-term monitoring is essential to capture the total genetic risk for disease development. For example, one study of monozygotic twins found that by the age of 60 years, there was greater than $65 \%$ concordance for T1D-i.e., when one twin is afflicted, it is more likely that the other twin will eventually develop the disease (19). In the same study, concordance of autoantibody positivity in the non-diabetic twin was nearly $80 \%$, again supporting the notion of genetic risk controlling the loss of immune tolerance to $\beta$ cell antigens.

The lack of complete concordance may indicate an additional role for epigenetic and/or stochastic influences due to antigenic receptor gene recombination events. In addition, epidemiological studies support a role for environmental factor(s) influencing disease progression. A number of large consortium studies have been conducted or are currently underway around the world (e.g., TrialNet, TEDDY, DAISY, BABYDIAB, and Pre-Point) to monitor disease progression and potentially, intervene in those identified as being at high-risk for disease development (27-31). From these studies, environmental influences have been reported to affect disease incidence or rate of progression, including enteroviral triggers, lack of protective exposures, and the influence of various components of Westernized diets. Many of these modifying factors impact pathways with associated genetic risk variants (e.g., Tyk2 and IFIH1 in response to viral infections), further supporting their potential importance (32). Thus, T1D is principally a genetic disease with environmental exposures influencing progression. These combined influences support the notion of a complex multifactorial disease, yet ultimately beg the question: Why do we not better understand the etiology and pathogenesis of human T1D? Even though the human genome is complex, it is still a finite collection of variables. In principle, utilization of "big data" approaches involving GWAS, biomarker studies, and expression profiling, when paired with robust computational capabilities, should be able to reveal a clear molecular signature, and from this signature, we should be able to progress through reductionist approaches to reveal pathways of disease.

This theoretical solution to the problem of complex autoimmune diseases is hindered by a number of fundamental challenges. Foremost, heretofore there have been no experimental systems available to study individual risk variants in human subjects. For T1D, where approximately 57 different genetic regions confer some portion of genetic risk (immunobase.org, July 2017) $(3,20-26)$, it is not possible to study one gene at a time without incurring significant epistatic effects from other risk genes. The likelihood of finding two individuals differing at only one risk gene (i.e., one person with the protective allele and one person with the risk allele) while having identical variants at the remaining 56 risk regions is infinitesimally small. A more practical approach would be to reduce the number of genetic loci being studied to include only those with the largest odds ratios (ORs). Even here, the problem is magnified by the fact that some of the most highly associated risk genes beyond the HLA [e.g., protein tyrosine phosphatase, non-receptor type 22 (PTPN22)] have a low minor allele frequency, even among T1D subjects. For North American and European T1D subjects, the frequency of individuals with homozygosity for the risk variant of PTPN22 (1858T at rs2476601) ranges from 0.6 to $3.7 \%$ (33). Moreover, 


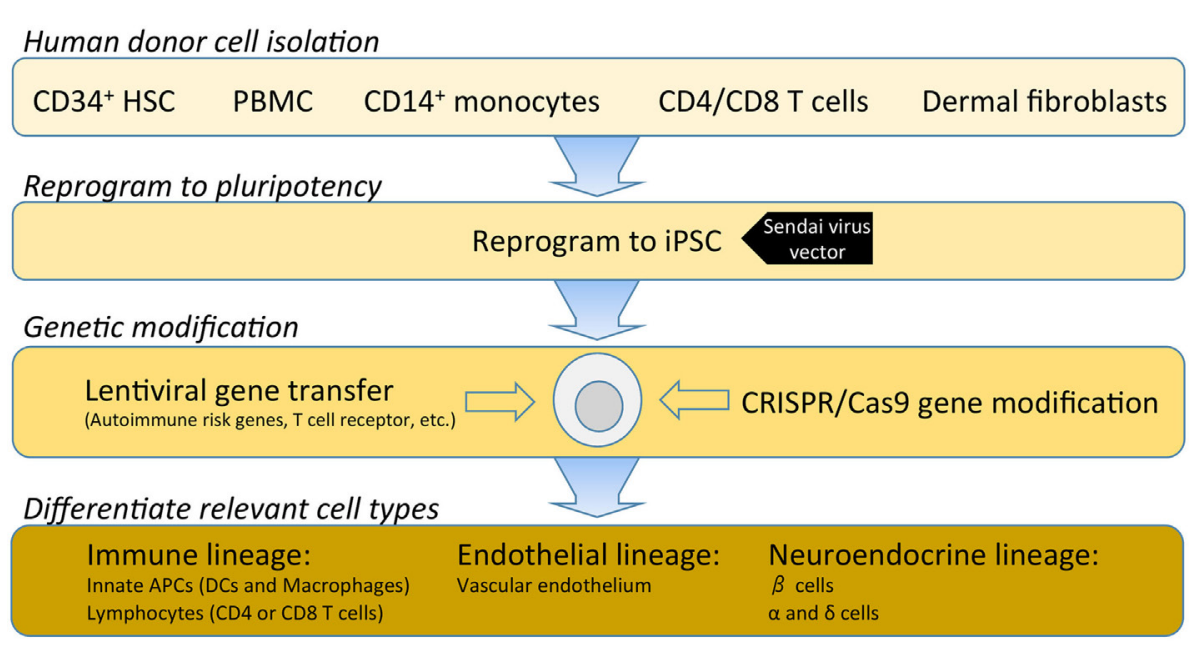

FIGURE 2 | A hypothetical outline for establishing an isogenic disease-in-a-dish workflow. Induced pluripotent stem cell (iPSC) stable cell lines can be generated from several different somatic cell types depending on specimen availability. Traditionally, dermal fibroblasts from skin biopsy were utilized; however, this is being replaced by less invasive samples such as freshly isolated or cryopreserved peripheral blood mononuclear cells (PBMCs). PBMCs can be enriched for various populations such as $\mathrm{CD} 34^{+}$hematopoietic stem cells, $\mathrm{CD} 14^{+}$monocytes, T cells, or reprogrammed as a bulk population. Where a pre-re-arranged T-cell receptor (TCR) is desired, antigen-specific CD4 or CD8 T cells can be used so that iPSC-derived T cells will clonally express the desired TCR with a naive T-cell phenotype. Several commercial platforms for iPSC reprogramming are currently available. Non-integrating Sendai virus vectors provide a safe and efficient means for iPSC reprogramming of human primary cells. Following reprogramming into IPSC, gene modification enables researchers to investigate disease-associated risk variants and/or over-express or knockdown genes to modulate pathways. Once gene modifications are confirmed, validated protocols for differentiation of immune, endothelial or neuroendocrine lineages are utilized to interrogate the specific effects of each gene variant in several disease-relevant cell types.

genes associated with T1D risk encode proteins that cluster within biological processes and/or pathways, posing a considerable challenge when analyzing the impact of a given risk variant.

Currently, 57 genomic regions that are defined by 104 SNPs [some SNPs identify the same linkage disequilibrium block] are significantly associated with T1D according to immunobase.org. The set of 64 T1D candidate gene variants from 57 SNP-tagged regions listed in Table 1 was analyzed using the Protein ANalysis THrough Evolutionary Relationships gene ontology tool (pantherdb.org) $(34,35)$. Not surprisingly, pathway analysis revealed a significant enrichment for genes involved in immune processes $(P=9.9 \mathrm{E}-11)$, where 26 of the 64 candidate genes contribute to immune function. The immune system is highly dynamic and integrates signals from antigenic receptors, adhesion molecules/ integrins, costimulatory molecules, and cytokine/chemokine receptors. These events in turn lead to signal transduction events that are also significantly enriched as a defined pathway. Based on our analysis, 32 of the 64 T1D candidate genes are implicated in cellular signaling $(P=9.25 \mathrm{E}-03)$ (Data File $\mathrm{S} 1$ in Supplementary Material). Considering the role of cross-talk between signaling pathways, it is evident that heterogeneous genetic risk will result in complex downstream effects on cell signaling and functions.

As a specific example of immune signaling pathway cross-talk, we consider one gene that encodes a protein with known effects on cytokine receptor signaling. SH2B3 encodes a protein phosphatase Lnk that regulates Janus kinase/signal transducers and activators of transcription (JAK/STAT) signaling. The risk variant of $\mathrm{SH} 2 \mathrm{~B} 3$ ( $T$ at rs3184504) encodes a modified Lnk protein where arginine at amino acid 262 is replaced by tryptophan (R262W). Lnk is a regulator of Jak2 signaling in myeloid cells (36-38), and the T1D risk SNP for SH2B3/Lnk is associated with altered expression of key elements of IFN $\gamma$ signaling including signal transducer and activator of transcription 1 (STAT1) (39). Furthermore, the target of Lnk, Jak2, is a cytosolic protein that transduces signals from a variety of cytokine receptors including IL-6, IL-13, G-CSF, IL-12, IL-23, granulocyte-macrophage colony-stimulating factor (GM-CSF), EPO, IL-3, and IL-5 $(40,41)$. Thus, the specific effect(s) of $\mathrm{Lnk}^{\mathrm{R} 262 \mathrm{~W}}$ upon immune cell function are difficult to predict. Adding to this inherent complexity, additional T1D risk genes/proteins are likely to co-regulate the same pathways as Lnk. For example, at least three T1D candidate genes, Tyk2, SOCS1, and IL10, encode proteins with known roles in modulating JAK/ STAT signaling. The interplay of different alleles of each protein will likely modify the effect of Lnk. This example highlights the need for an experimental system that mitigates the epistatic effects of related genes/proteins so that observed phenotypes are attributed to the gene of interest alone.

In addition to the number of variants and overlapping pathways noted above, there are additional layers of complexity at the cellular level. Specifically, it is poorly characterized how a given risk variant may impact function within various innate or adaptive immune subsets. For example, a gene that regulates JAK/STAT signaling in antigen-presenting cells (APCs) such as dendritic cells (DCs) may have an entirely different biological effect in lymphocytes. Moreover, the impact of a gene variant may be combinatorial to multiple cell types that conspire to drive autoimmunity. Furthermore, some genes may affect the $\beta$ cells themselves, endothelial cells, or other cells such as neurons (42).

The central pathophysiological mechanism of T1D entails at least three major tissue types-immune, endothelial, and 
TABLE 1 | Genetic variants associated with type 1 diabetes and other common autoimmune diseases.

\begin{tabular}{|c|c|c|c|c|c|c|c|c|}
\hline Chromosome & Marker & Gene & Feature & $\begin{array}{l}\text { Coding } \\
\text { variant }\end{array}$ & $\begin{array}{l}\text { Amino acid } \\
\text { variation }\end{array}$ & Additional notes & Region & $\begin{array}{l}\text { Other associated } \\
\text { diseases }\end{array}$ \\
\hline \multirow[t]{5}{*}{1} & rs2476601 & PTPN22 & Exon & Y & R620W & & $1 p 13.2$ & ATD/CRO/JIA/RA/ \\
\hline & rs6679677 & & $3^{\prime}$ region-intergenic & $\mathrm{N}$ & & & & SLE/AAVIT \\
\hline & rs6691977 & CAMSAP2 & Intron & $\mathrm{N}$ & & & $1 q 32.1$ & \\
\hline & rs3024505 & IL10 & $3^{\prime}$ region-intergenic & $\mathrm{N}$ & & & $1 \mathrm{q} 32.1$ & CRO/SLE/UC/IBD \\
\hline & rs3024493 & & Intron & $\mathrm{N}$ & & & & \\
\hline \multirow[t]{8}{*}{2} & rs35667974 & $|F| H 1$ & Exon & Y & I923V & & $2 q 24.2$ & PSO/SLE/UC/ \\
\hline & rs2111485 & & $3^{\prime}$ region-intergenic & $\mathrm{N}$ & & & & $\mathrm{IBD} / \mathrm{VIT}$ \\
\hline & rs1990760 & & Exon & Y & A946T & & & \\
\hline & rs11571316 & CTLA4 & $5^{\prime}$ region-intergenic & $\mathrm{N}$ & & & 2q33.2 & ATD/CEL/RA \\
\hline & rs3087243 & & $3^{\prime}$ region-intergenic & $\mathrm{N}$ & & & & \\
\hline & rs4849135 & ACOXL & Intron & $\mathrm{N}$ & & & $2 q 13$ & \\
\hline & rs478222 & EFR3B & Intron & $\mathrm{N}$ & & & $2 p 23.3$ & \\
\hline & rs9653442 & AFF3 & 5' region-intergenic & $\mathrm{N}$ & & & $2 q 11.2$ & RA \\
\hline 3 & rs113010081 & $\begin{array}{l}\text { CCR5 and } \\
\text { CCRL2 }\end{array}$ & 3' region-intergenic & $\mathrm{N}$ & & & 3p21.31 & CEL/UC \\
\hline \multirow[t]{6}{*}{4} & rs2611215 & LINC01179 & $5^{\prime}$ region-intergenic & $\mathrm{N}$ & & & $4 q 32.3$ & \\
\hline & rs75793288 & CTNNB1 & Intron & $\mathrm{N}$ & & $\begin{array}{l}5^{\prime} \text { of ADAD1 and } 3^{\prime} \\
\text { of IL2 }\end{array}$ & $4 q 27$ & CEL/CRO/UC \\
\hline & rs6827756 & & Intron & $\mathrm{N}$ & & $\begin{array}{l}5^{\prime} \text { of ADAD1 and } 3^{\prime} \\
\text { of } \| 2\end{array}$ & & \\
\hline & rs4505848 & & Intron & $\mathrm{N}$ & & $\begin{array}{l}5^{\prime} \text { of ADAD1 and } 3^{\prime} \\
\text { of IL2 }\end{array}$ & & \\
\hline & rs17388568 & $A D A D 1$ & Intron & $\mathrm{N}$ & & $3^{\prime}$ of IL2 & & \\
\hline & rs10517086 & No gene & Intergenic-H3K27Ac rich & $\mathrm{N}$ & & & $4 p 15.2$ & \\
\hline 5 & rs11954020 & ILTR & $3^{\prime}$ region-intergenic & $\mathrm{N}$ & & & $5 p 13.2$ & \\
\hline \multirow[t]{9}{*}{6} & rs9388489 & CENPW & Intron & $\mathrm{N}$ & & & $6 q 22.32$ & \\
\hline & rs1538171 & & Intron & $\mathrm{N}$ & & & & \\
\hline & rs9375435 & & Intron & $\mathrm{N}$ & & & & \\
\hline & rs597325 & $\mathrm{BACH} 2$ & Intron & $\mathrm{N}$ & & & $6 q 15$ & ATD/MS/RA \\
\hline & rs11755527 & & Intron & $\mathrm{N}$ & & & & \\
\hline & rs72928038 & & Intron & $\mathrm{N}$ & & & & \\
\hline & rs924043 & No gene & Intergenic & $\mathrm{N}$ & & & $6 q 27$ & \\
\hline & rs6920220 & TNFAIP3 & $5^{\prime}$ region-intergenic & $\mathrm{N}$ & & & 6q23.3 & RA/SLE/UC/IBD \\
\hline & rs1738074 & TAGAP & Exon & $\mathrm{N}$ & SYN & & $6 q 25.3$ & CEL/MS \\
\hline \multirow[t]{3}{*}{7} & rs7804356 & SKAP2 & Intron & $\mathrm{N}$ & & & $7 p 15.2$ & \\
\hline & rs4948088 & $C O B L$ & $3^{\prime}$ region-intergenic & $\mathrm{N}$ & & & $7 p 12.1$ & \\
\hline & rs62447205 & $I K Z F 1$ & Intron & $\mathrm{N}$ & & & $7 p 12.2$ & \\
\hline \multirow[t]{3}{*}{9} & rs10758593 & GLIS3 & Intron & $\mathrm{N}$ & & & $9 p 24.2$ & \\
\hline & rs7020673 & & Intron & $\mathrm{N}$ & & & & \\
\hline & rs6476839 & & Intron & $N$ & & & & \\
\hline \multirow[t]{10}{*}{10} & rs722988 & $N R P 1$ & $3^{\prime}$ region - intergenic $-\mathrm{H} 3 \mathrm{~K} 27 \mathrm{Ac}$ rich & $\mathrm{N}$ & & & $10 p 11.22$ & \\
\hline & rs11258747 & $P R K C Q$ & Exon & $\mathrm{N}$ & SYN & & 10p15.1 & \\
\hline & rs61839660 & IL2RA & Intron & $\mathrm{N}$ & & & 10p15.1 & MS/RA \\
\hline & rs2104286 & & Intron & $\mathrm{N}$ & & & & \\
\hline & rs12251307 & IL2RA and & $5^{\prime}$ of RMB17 and 3' of IL2RA & $\mathrm{N}$ & & & & \\
\hline & rs41295121 & $R B M 17$ & $5^{\prime}$ of RMB17 and $3^{\prime}$ of IL2RA & $\mathrm{N}$ & & & & \\
\hline & rs7090530 & & $5^{\prime}$ of RMB17 and $3^{\prime}$ of IL2RA & $\mathrm{N}$ & & & & \\
\hline & rs10795791 & & $5^{\prime}$ of RMB17 and $3^{\prime}$ of IL2RA & $\mathrm{N}$ & & & & \\
\hline & rs12416116 & RNLS & Intron & $\mathrm{N}$ & & & 10q23.31 & \\
\hline & rs10509540 & & $3^{\prime}$ region-intergenic & $\mathrm{N}$ & & & & \\
\hline \multirow[t]{5}{*}{11} & rs72853903 & INS & $5^{\prime}$ region-intergenic $-\mathrm{H} 3 \mathrm{~K} 27 \mathrm{Ac}$ rich & $\mathrm{N}$ & & & $11 p 15.5$ & \\
\hline & rs689 & & Intron & $\mathrm{N}$ & & & & \\
\hline & rs7111341 & & $5^{\prime}$ region-intergenic & $\mathrm{N}$ & & & & \\
\hline & rs7928968 & & $3^{\prime}$ region - intergenic & $\mathrm{N}$ & & & & \\
\hline & rs694739 & $B A D$ & 5' region-intergenic & $\mathrm{N}$ & & $\begin{array}{l}5^{\prime} \text { of } \mathrm{CCDC} 88 \mathrm{~B} \text { and } \\
3^{\prime} \text { of PRDX5 }\end{array}$ & $11 \mathrm{q} 13.1$ & $\mathrm{CRO} / \mathrm{MS} / \mathrm{AA}$ \\
\hline
\end{tabular}


TABLE $1 \mid$ Continued

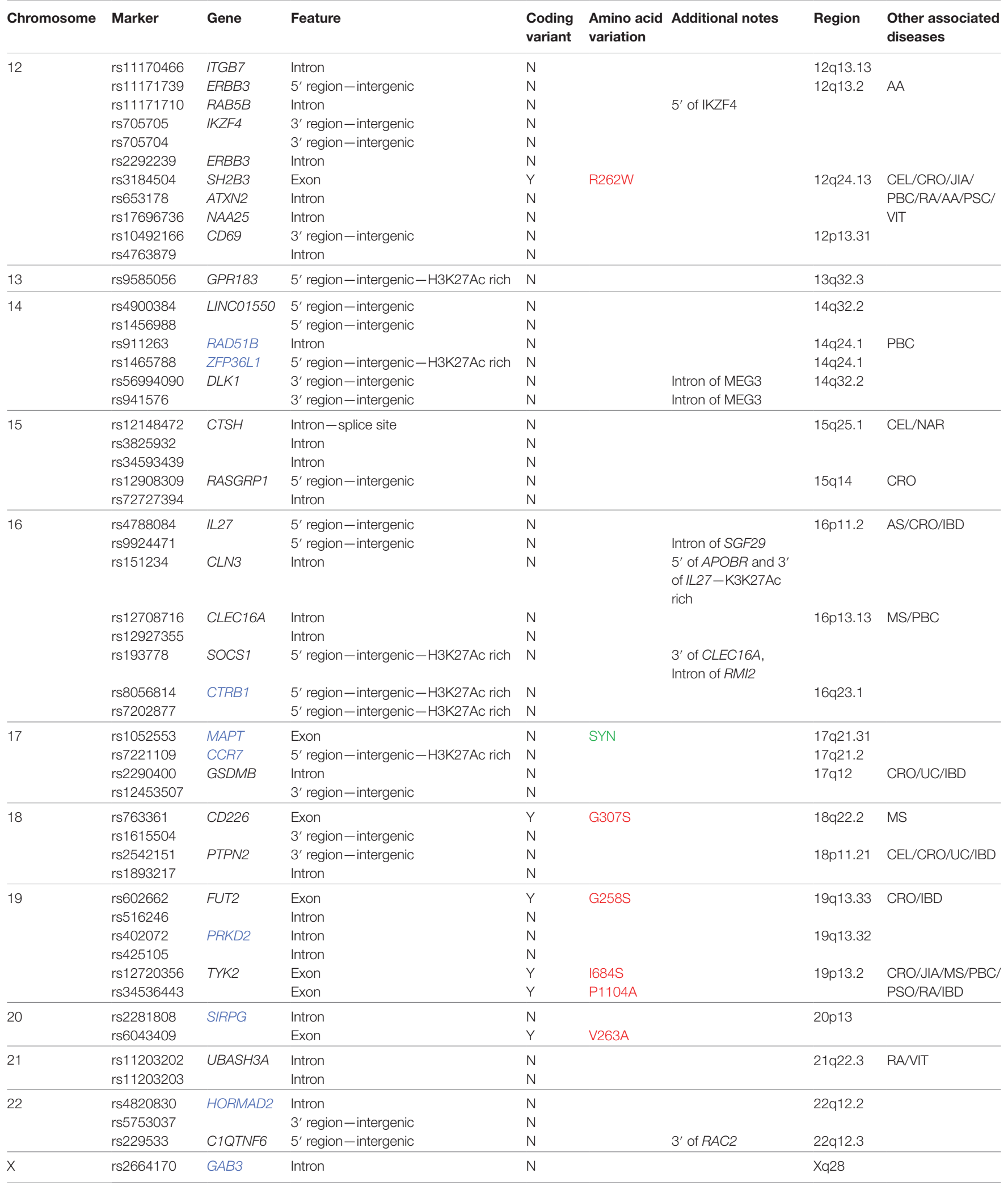

Genes and markers were derived from immunobase.org (3, 20-26). The genes indicated in blue text were imputed from information derived from the University of California Santa Cruz genome browser (genome.ucsc.edu). Amino acid variations (red text) were identified for single nucleotide polymorphism (SNP) variants by downloading the spliced coding sequences from genome browser and translating in SnapGene software. SYN (green text) indicates synonymous variation in an exon. Genomic region and disease information displayed were derived from Immunobase. ATD, autoimmune thyroid disease; CRO, Crohn's disease; JIA, juvenile idiopathic arthritis; RA, rheumatoid arthritis; SLE, systemic lupus erythematous; AA, alopecia areata; VIT, vitiligo; UC, ulcerative colitis; IBD, inflammatory bowel disease; PSO, psoriasis; CEL, celiac disease; MS, multiple sclerosis; PBC, primary biliary cirrhosis; PSC, primary sclerosing cholangitis; NAR, non-allergic rhinitis; AS, ankylosing spondylitis. 


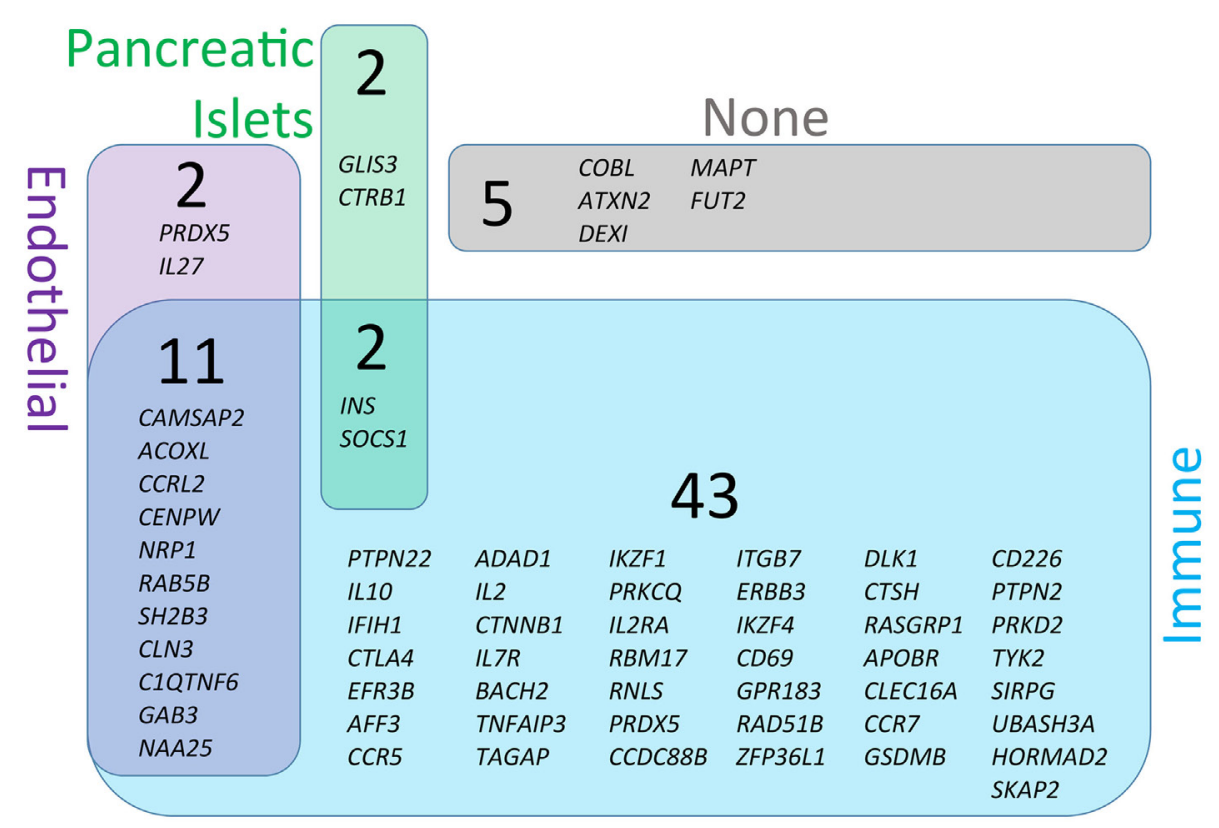

FIGURE 3 | Genetic susceptibility risk variants identified in type 1 diabetes (T1D). The current list of gene regions that have been associated with T1D through genome-wide association studies were collected from the ImmunoBase resource (www.immunobase.org). Individual single-nucleotide polymorphisms (SNPs) corresponding to candidate genes were identified from the ImmunoBase T1D data set. In addition, every SNP tag was queried on the University of California Santa Cruz Genome Browser (GRCh38; genome.ucsc.edu) to identify additional genes in each SNP-tagged region. The complete list of regions and genes are compiled in Table 1. Each SNP-associated gene was queried on the GeneVestigator database to identify the top 10 tissues with highest expression of each gene (genevisible. com/search). For each gene it was determined if high-expressing tissues included any one or combination of relevant tissues: immune (blue), endothelial (purple), or pancreatic islets (green). The size of regions in Venn diagram represents the relative abundance of genes expressed in each tissue type. Five genes were not highly expressed by any of the relevant tissue types (indicated as none, gray).

pancreatic (Figure 1). To better understand which cells are likely to be affected by each T1D candidate gene, we analyzed all genes from Table 1 for cell/tissue expression profiles using the online GeneVisible tool (genevisible.com) (43) that queries tens of thousands of curated human gene expression experiments. As seen in Figure 3, the majority of T1D candidate genes are expressed most highly in immune cells, but a small number of genes are preferentially expressed in endothelial or pancreatic cell lineages. Notably, 13 genes are highly expressed in multiple lineages. Isolating the effect of candidate genes in relevant cell types should be a goal for the isogenic cellular experimental system described herein.

A number of T1D-associated SNPs encode missense mutations within gene exons, presumably altering protein stability, interactions, or function (Table 1); here, the path to dissect the impact of variants on biological processes is straightforward. However, the vast majority of risk loci reside in non-coding regions of the genome and careful studies must be undertaken to first dissect the causative variant(s) from each tag SNP locus and then determine whether any given SNP exerts its impact in a cis or trans manner to alter gene expression (5). One such study by Ram et al. recently applied a systems genetics approach to dissect the impact of putative risk SNPs on gene expression in purified and activated cell lines. The authors mapped cis-acting expression quantitative trait loci (eQTL) and found 24 non-HLA loci that significantly affected the expression of 31 transcripts in at least one cell type from Epstein-Barr virus-transformed
B cells and $\mathrm{CD}^{+}$or $\mathrm{CD} 8^{+} \mathrm{T}$ cells (44). They went on to describe an additional 25 trans-acting loci that impacted 38 transcripts. Of note, many of the SNPs associated with risk are located within promoter or enhancer regions of their candidate gene (3). These studies provide a framework from which additional mechanistic studies can now be conducted in isogenic cellular systems.

To begin to address these challenges, the research community needs robust platforms to study the effects of individual risk alleles in various cell types under controlled conditions. With the advent of iPSC technologies and genome-editing tools, this once theoretical approach now provides an efficient method to analyze disease mechanisms and identify causal gene variants (Figure 4). By creating a disease-in-a-dish experimental platform, we and others have started to dissect the individual contributions of T1D risk genes in specific cell types. Harnessing this information will allow researchers to derive rational therapeutics targeting checkpoints in key pathways.

\section{DEFECTIVE IMMUNE TOLERANCE IN T1D}

Autoimmune diseases, including T1D, result from a breakdown in the pathways that maintain a state of immune homeostasis, commonly referred to as immune tolerance (1). The mechanisms controlling this process involve both central and peripheral tolerance mechanisms (e.g., thymic selection and immune checkpoints, respectively). Effective immunity requires the 


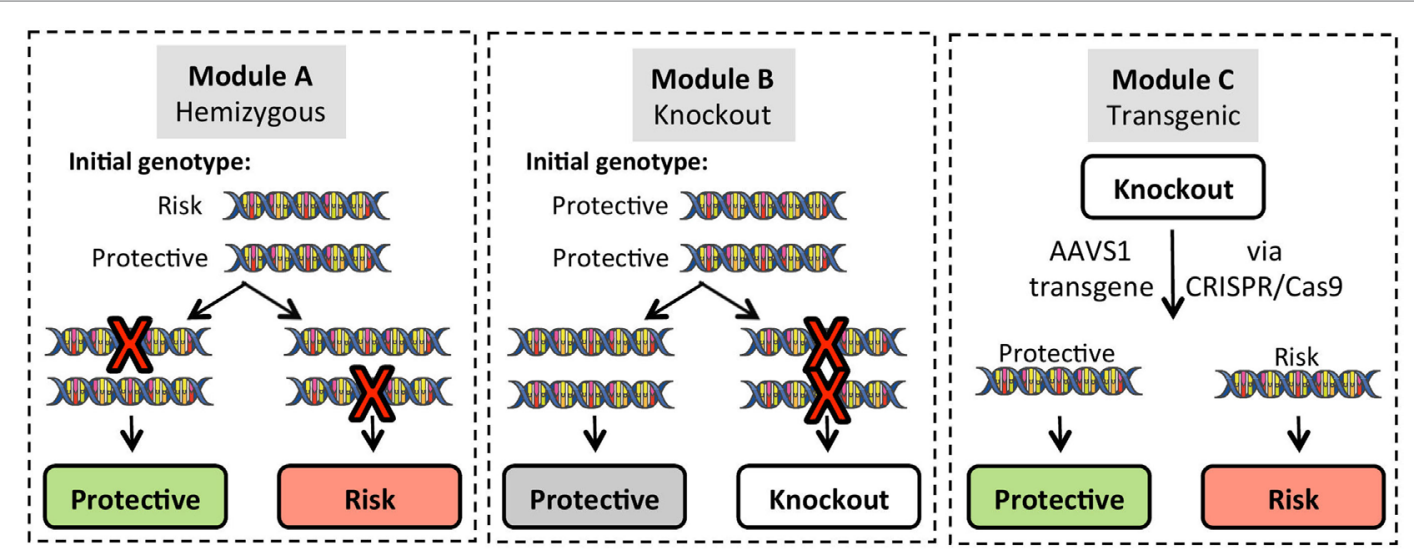

FIGURE 4 | Gene modification strategies for use in induced pluripotent stem cell (iPSC) lines. Three basic strategies can be employed for gene editing. To create single allele homozygous expression (hemizygous) lines, Module $A$ targets a single allele of the gene of interest (GOI) in iPSC lines that are heterozygous for the risk variant. Targeting efficiency for hemizygous clones is approximately $20 \%$ of green fluorescent protein positive puromycin resistant clones, and allele targeting is random so that either the protective or risk allele can be modified. Module B generates complete knockout of the GOI on a background of homozygous protective alleles. Module $\mathrm{C}$ utilizes GOI-knockout lines to re-express either the protective or risk variant of the GOI using a CRISPR/Cas9 platform that targets integration into the adeno-associated virus integration site 1 (AAVS1) on chromosome 19.

capacity to respond to a vast array of antigens from pathogens, all while functionally limiting host responses to self-tissues and commensal microorganisms. In health, the adaptive immune system consisting of T and B lymphocytes is edited to eliminate portions of the repertoire that acquire somatically re-arranged receptors with high binding affinity for self-antigens through clonal deletion. For $\mathrm{T}$ cells, this process is carried out in the thymus under the control of the autoimmune regulator (AIRE) (45). Medullary thymic epithelial cells (mTECs) expressing AIRE are thought to coordinate the expression of a select number of tissue-specific self-antigens (TSAs). These TSAs, when expressed by mTEC work in concert with APCs to eliminate high-affinity autoreactive T-cell receptors (TCRs) through negative selection. The thymus is also the site for the emergence of thymic CD4 ${ }^{+}$ regulatory $\mathrm{T}$ cells (tTregs), a population of cells that express the master Treg-transcription factor FOXP3 (46). These tTregs seed the periphery, playing a key role in reinforcing immune tolerance. Rare monogenic mutations in AIRE and FOXP3 result in profound autoimmune conditions, referred to as autoimmune polyglandular syndrome-1 and immunodysregulation polyendocrinopathy enteropathy X-linked syndrome (IPEX), respectively (47). T1D is a common clinical manifestation of patients presenting with these severe mutations, supporting the essential role for these transcription factors in regulating immune tolerance to $\beta$ cells. To date, studies of thymic T-cell selection have largely been restricted to animal models. The development of isogenic cellular systems provides a unique opportunity to investigate molecular pathways that shape the human adaptive immune repertoire.

\section{ISOGENIC MODELS FOR STUDYING THYMIC SELECTION}

As noted earlier, the HLA region constitutes the major genetic risk locus in T1D (48). While this region has been known to confer risk for over four decades, the exact mechanisms by which variants in HLA influence disease pathogenesis remain poorly characterized. In addition to shaping the T-cell repertoire through the processes of positive and negative selection, the thymic developmental niche controls the composition and relative proportion of naive conventional $\mathrm{T}$ cells (Tconv) and tTregs that emerge to form the mature $\mathrm{CD}^{+} \mathrm{T}$ cell population (49). Little is currently known about how high-risk HLA haplotypes (e.g., HLA-DR3/ DR4-DQ8) shape the resulting T-cell repertoire, or for that matter, why the HLA-DRB1 ${ }^{\star} 15: 01-\mathrm{DQA} 1^{\star} 01: 02-\mathrm{DQB} 1^{\star} 06: 02$ haplotype is so dominantly protective in Caucasian populations (OR 0.03) (50). A prevailing theory presented by Eisenbarth and colleagues suggests that the key might lie within the tri-molecular complex of HLA class II molecules presenting peptides of insulin (specifically, the insulin B-chain ${ }_{9-23}$ ) for recognition by autoreactive TCRs (51). T1D DQ8 risk alleles and I-A $\mathrm{A}^{\mathrm{g} 7}$ of the non-obese diabetic (NOD) mouse tend to share non-polar residues in place of Asp at $\beta 57$ and preferentially bind peptides with acidic side chains in the P9 pocket of the MHC class II binding groove (52). Thus, these molecular interactions within distinct peptide binding pockets may either allow escape of potentially pathogenic autoreactive $\mathrm{T}$-cell clones from the thymus or potentially fail to generate the proper repertoire of protective tTregs capable of maintaining tolerance.

Together with HLA, additional candidate risk genes could also have an impact on thymic T-cell development. Specifically, at least three independent variants within the INS-IGF2 locus have been associated with risk for T1D (3). This region confers the second highest risk for disease following the HLA locus. Risk associated with the INS gene on chromosome 11p15.5 has been most commonly attributed to a variable number tandem repeat locus situated 596 bp 5' of INS (53). Protection from the class III allele has been attributed to a markedly higher level of insulin being expressed within the thymus (54). Insulin has been proposed as a primary or triggering auto-antigen in the NOD mouse model (55) and more recently in human T1D (56). Notably, T cells reactive 
to both native and hybrid insulin peptides, insulin conjugated with other $\beta$ cell antigens, were discovered within the islets of subjects with T1D (56-58). When considered in addition to the dominance of genetic risk conferred by the HLA, these significant observations lend additional support to the dominance of insulin epitopes as a primary auto-antigen in disease pathogenesis.

These reports highlight the need for mechanistic studies to ascertain how susceptibility alleles impact the process of thymic selection. Through the creation of isogenic systems involving human bone marrow progenitors, thymic organoids, mTECs, and APCs, novel avenues can now be explored to investigate genetic control of the human adaptive T-cell repertoire. Key polymorphisms may be altered by gene editing and genes and/or pathways may be "switched" on or off in a temporal fashion by the addition of chemical enhancers or repressors in either $\mathrm{T}$-cell precursors or thymic stroma. Not only will this provide key insight into pathogenic versus regulatory receptors but could also potentially provide an opportunity for the ex vivo education of $\mathrm{T}$ cells in isogenic thymic organoids for auto- and/or allo-tolerance induction strategies following $\beta$ cells regenerative or replacement therapies in T1D.

\section{MODELING ANTIGEN-SPECIFIC T-CELL RESPONSES}

Type 1 diabetes is most often described as a T-cell-mediated organ-specific autoimmune disease. This notion emanates from seminal experiments including the strong linkage to HLA, early animal model adoptive transfer experiments $(59,60)$, and the presence of autoreactive memory $\mathrm{T}$ cells within the insulitic lesion of organ donors with T1D $(12,14)$. Studies have been conducted to investigate and monitor autoreactive $\mathrm{T}$ cells in peripheral blood mononuclear cell (PBMC) of T1D subjects. To date, none of the commonly employed techniques have approached the sensitivity/ specificity and level of standardization observed for autoantibody assays validated by the diabetes antibody standardization program now known as the islet autoantibody standardization program (61-66). We would speculate that the major reason(s) for this inability to identify robust T-cell biomarkers results from both technical limitations of the current assays, along with the inherent biology of T cells. Our data profiling the TCR repertoire in T1D nPOD organ donors demonstrated only modest overlap in high frequency clonotypes between the pancreatic lymph nodes and spleen (as a surrogate of PBMC) (67). This was particularly striking for $\mathrm{CD}^{+} \mathrm{T}$ cells (mean $\pm \mathrm{SD} ; 9.2 \pm 7.0 \%$ of clones shared), with $\mathrm{CD}^{+} \mathrm{T}$ cells demonstrating significantly more TCR- $\beta$ complementarity determining region 3 amino acid sequence overlap among different tissues $(36 \pm 21 \%)$.

Studies to quantify antigen-specific $\mathrm{T}$ cells with ELISpot or MHC-multimer reagents have demonstrated the rare nature of these cells in PBMC (in the range of 1:50,000-1:1,000,000) (68). This presents a number of challenges when trying to identify key auto-antigen targets and peptides important during the natural history of disease. To address this particular limitation, we have co-opted an approach pioneered in the cancer immunotherapy field to generate large numbers of tumor-antigen-specific T cells. Specifically, we have generated lentiviral contructs that express full TCR- $\alpha$ and $\beta$ chains in multi-cistronic expression cassettes. This technique is effective for redirecting the specificity of primary human Tconv and Tregs as well as CD8 ${ }^{+} \mathrm{T}$ cells (69). Recent advances in gene editing and receptor engineering have advanced this field to create programmable circuits for studying T-cell specificity and effector functions (70). Importantly, we have recently employed TCR gene transfer to directly test the cytotoxic activity of glucose- 6 -phosphatase-reactive $\mathrm{CD}^{+} \mathrm{T}$ cells to target and lyse $\beta$-Lox 5 cells or primary $\beta$ cells in vitro (71). From a therapeutic perspective, our current efforts demonstrate that human Tregs can be redirected to recognize $\beta$ cell auto-antigens in the context of DR3/DR4-DQ8 and remain highly suppressive in vitro to Tconv recognizing a shared peptide or in a bystander fashion (72). The application of novel single cell/clone analysis platforms, when used in concert with isogenic cellular systems, will allow researchers to quickly move from in silico TCR- $\alpha / \beta$ sequence information to unlimited numbers of antigen-specific $\mathrm{T}$ cells to expedite auto-antigen discovery and functional studies.

iPSCs can be used for yet another approach to generate a large number of antigen-specific T cells and to further study mechanisms of thymic selection. A small number of groups have successfully differentiated iPSCs into functional T cells. iPSC derived from a single $\mathrm{CD}^{+} \mathrm{T}$-cell clone have been re-differentiated into naive and eventually highly functional CTLs (73). This application has emerged as a particularly potent means to not only bolster the number of antigen-specific $\mathrm{T}$ cells but also correct the anergic and senescent phenotype common to tumor-infiltrating $\mathrm{T}$ cells in cancer, and while early studies were focused on generation of $\mathrm{CD}^{+}$CTLs for targeting virus-infected cells (73) or tumors (74), the methods could be adapted to focus on auto-antigen-specific $\mathrm{T}$ cells. When iPSC derived from non-T cells (not bearing rearranged TCR genes) are used for T-cell differentiation, a broad diversity of TCR rearrangement events is possible (75).

Differentiation protocols for iPSC-derived $\mathrm{T}$ cells require culture on the murine stromal cells line OP9 expressing the Notch ligand protein DL1 (74). The quality of iPSC-derived T cells has been incrementally improved by altering culture conditions, for example activating CD4/CD8 double positive iPSC-derived thymocytes via CD3 to enhance CTL killer activity (76). Today, detailed protocols are available for the differentiation of antigenspecific $\mathrm{CD}^{+} \mathrm{T}$ cells from iPSC (73). To date, advances in singlepositive $\mathrm{CD}^{+} \mathrm{T}$ cells have not approached the same progress as CTLs, yet efficient protocols to generate $\mathrm{CD} 4^{+} \mathrm{T}_{\mathrm{H}}$-cell populations are expected. For example, advances in deriving human thymic epithelial cells from iPSCs (77) could enhance in vitro differentiation of $\mathrm{CD}^{+}$and $\mathrm{CD} 8^{+} \mathrm{T}$ cells by providing the full repertoire of human soluble and membrane-associated growth factors. In addition, iPSC-derived thymic epithelia will enable more precise studies of how disease-associated gene variants impact thymic selection by regulating specific processes such as auto-antigen expression during negative selection. The capacity to grow and differentiate large numbers of isogenic antigen-specific $\mathrm{T}$ cells ( $>10^{9}$ cells), without the typical constraints of primary human T-cell clones opens up the potential for gene editing and extensive functional studies. Thus, we are nearing the point where isogenic 
iPSC systems can be used to study human T-cell development at a mechanistic level that was previously only attainable in animal models.

\section{MODELING INNATE IMMUNE RESPONSES}

Development of auto-antigen-specific T cells requires more than a failure of thymic negative selection. Naive T cells in the periphery must be primed by professional APCs. DCs are specialized APCs with potent abilities to initiate antigen-specific $\mathrm{CD} 4^{+}$and $\mathrm{CD}^{+}$ $\mathrm{T}$-cell responses. To elicit $\mathrm{CD} 4^{+} \mathrm{T}$ cells priming, activation, proliferation, and effector function, DCs must first capture antigens via phagocytosis or micropinocytosis. It can be envisioned that this antigen capture in T1D manifests through DCs phagocytosing dead/dying $\beta$ cells or exosomes derived from $\beta$ cells.

Several genes associated with T1D risk are expressed in myeloid lineages including monocytes, macrophages, and DCs, and it is likely that at least some of the immune pathogenesis of T1D arises from the innate end of the immune system. Differences in innate immune function could emanate from dysregulated antiviral or type 1 interferon (T1-IFN) responses, altered co-stimulation, changes in antigen acquisition, or enhanced expression of proinflammatory cytokines. As an example, a T1-IFN response signature has been observed preceding T1D onset in high-risk populations (32). The NOD Rip-LCMV mouse model corroborates this finding, where IFN- $\alpha$ is critical for progression of T1D (78). Furthermore, some enteric viral infections have been associated with risk for T1D. In NOD mice, rotavirus infection can accelerate T1D in a T1-IFN-dependent manner (79). In humans, a growing number of studies have reported associations between enterovirus infection and T1D (80-84). Thus, genes that regulate the innate response to viruses including T1-IFN expression or signaling could mediate T1D risk by altering innate immune function.

\section{T1D RISK GENES THAT MODULATE ANTIVIRAL IMMUNITY}

PTPN22, commonly associated with modifying receptor signaling in T and B cells, is also reported to alter the way that DCs respond to danger signals such as bacterial lipopolysaccharide by modulating TRAF3 signaling and T1-IFN production (85). In lupus, the risk variant of PTPN22 tagged by rs2476601, the same variant that is associated with T1D (Table 1), is associated with altered TLR7-induced T1-IFN production (86).

A major counter-regulator of IFN signaling is the regulatory cytokine IL-10. Indeed, IL-10 is so potent for protection of host cells from CTL-mediated killing that many DNA viruses have evolved viral homologs of IL-10 to protect them from antiviral immunity (87). The T1D risk locus defined by the SNPs rs3024504 and rs3024493 includes IL10 (Table 1). A protective role for IL-10 in murine T1D has been established through transgenic NOD mice that over-express IL-10 or where exogenous administration of recombinant IL-10, plasmid DNA encoding IL-10, or cells expressing IL-10 have been used (88-90). Moreover, in vitro, IL-10 protects human islets from the cytotoxic effects of inflammatory cytokines (91).
From the innate arm of the immune system, variant alleles of the T1-IFN receptor downstream signaling protein Tyk2, the cytosolic viral RNA sensor IFIH1 (MDA5), the macrophage lysosomal enzyme cathepsin $\mathrm{H}$, and the phosphatase $\mathrm{SH} 2 \mathrm{~B} 3$ are also associated with risk for T1D (Table 1). Collectively, these genes along with PTPN22, IL10, SOCS1 and potentially others signify a major role for innate immune responses in T1D pathogenesis. Similar to T-cell responses, isogenic systems are critical for understanding how each risk variant affects innate immune function.

\section{ISOGENIC MODELING OF INNATE- ADAPTIVE IMMUNE INTERACTIONS}

Innate APCs participate in the initiation of immune responses; however, they also play an important role in sustaining an ongoing adaptive immune response. Interaction of APCs with antigen-specific $\mathrm{CD}^{+} \mathrm{T}$ cells provides bi-directional signals to both cell types. $\mathrm{CD}^{+} \mathrm{T}$ helper type $1\left(\mathrm{~T}_{\mathrm{H}} 1\right)$ cells are important enhancers of macrophage function. Secreted cytokines (e.g., IFN- $\gamma$ ) and membrane-associated so-stimulatory molecules [e.g., CD40 ligand (CD40L)] expressed by $\mathrm{T}_{\mathrm{H}} 1$ cells arm macrophages to more effectively kill microbes or infected cells. In T1D pathogenesis, there are essential roles for $\mathrm{T}_{\mathrm{H}} 1 \mathrm{~T}$ cells, IFN- $\gamma, \mathrm{CD} 40$ CD40L, and intra-islet macrophages. Where IFN- $\gamma$-secreting $\mathrm{T}_{\mathrm{H}} 1$ cells encounter macrophages in the islets of NOD mice, the macrophages become activated and produce inflammatory cytokines and reactive oxygen species that kill $\beta$ cells (92).

Most human studies of macrophages and DCs rely on two sources of cells-transformed monocytic leukemia cell lines or peripheral blood monocytes isolated from venipuncture. Some studies utilize alveolar macrophages derived from broncioloaviolar lavage or other specialized macrophages that are collected and studied ex vivo; however, sample number and size are limiting. PBMCs, while plentiful in number, easy to differentiation into macrophages or DCs, and available from large cohorts due to the low risk of venipuncture, are not ideal for all genetotype:phenotype studies where as discussed above, isogenic systems are key. This is further complicated in monocytes, macrophages and DCs because they are non-dividing cells in culture and generally difficult to modify genetically. iPSCs offer a solution to both problems because they are relatively simple to modify by lentiviral gene delivery or CRISPR/Cas9 and they are effectively immortal in culture. Differentiation of monocytes from iPSC offers the opportunity to study individual T1D risk genes in macrophages and DCs with unprecedented clarity. Protocols for differentiation of iPSC-derived monocytes vary widely from a simple two-cytokine mix of IL-3 and macrophage colonystimulating factor (MCSF) (93) to a complex mix of cytokines and growth factors (94). Both protocols yield monocytes that can be differentiated into macrophages or DCs using standard conditions (MCSF for macrophages; GM-CSF + IL-4 for DCs), and the differentiated cells retain functional properties of peripheral blood monocyte-derived cells. Thus, isogenic systems now allow researchers to study the effects of a gene variant in either adaptive or innate immune cells alone, but more importantly, we can now determine how T1D risk variants impact innate/adaptive 
immune interactions, which are more representative of in vivo disease etiology.

\section{THE $\beta$ CELL AND ISLET MICROENVIRONMENT}

While the immune system is thought to serve as the primary pathogenic mediator of T1D, there are events leading up to that cytotoxic cell-cell interaction that must occur to facilitate autoreactive T-cell destruction of $\beta$ cells. Specifically, autoreactive $\mathrm{CD}^{+} \mathrm{T}$ cells must home from the bloodstream and tether to inflamed endothelium creating firm adhesion contacts, extravasate through the endothelial membrane into the extracellular matrix (ECM), and eventually survey the microenvironment for their cognate antigens presented by HLA class I hyperexpressing islets (95). To completely model the events driving immune destruction of $\beta$ cells in vitro, culture systems are needed where both $\beta$ cells and endothelium can be derived. Extensive research has focused on the differentiation of functional, glucoseresponsive, insulin-secreting $\beta$ cells from human embryonic stem cells (hES) (96-98) as well as iPSC (99-103). Established protocols rely upon multistage culture of pluripotent cells to derive definitive endoderm followed by progressive differentiation of pancreatic endoderm. Often the $\beta$ cells (or $\beta$-like cells) are transplanted to immunodeficient mice where further maturation and functional development continue in vivo (104-106). More recently, methods have been developed to convert human fibroblasts into $\beta$-like cells by compressing the differentiation protocol so that iPSC reprogramming and differentiation of endoderm occur simultaneously (107). Many of these efforts are being carried out with the eventual goal of replacing $\beta$ cell mass in T1D patients or utilizing xenotransplantation into humanized mice to model T1D pathogenesis. An alternative is to use $\beta$-like cells and immune cells from syngeneic iPSC to model immune destruction of $\beta$ cells in vitro. This process could include endothelial layers (108-110), or ECM barriers that mimic key structures involved in immune homing in vivo. The advantage of this specific approach would include the ability to test novel strategies for blocking cellular adhesion, chemotaxis to inflammatory chemokines (e.g., IP-10), as well as potentially blocking degradation of the ECM needed for T-cell migration into the islet microenvironment.

\section{ISOGENIC CELLULAR SYSTEMS: A TOOL FOR EXPEDITING TRANSLATIONAL THERAPIES}

The emerging fields of iPSC and isogenic cellular systems, when coupled with genome-editing technologies, hold great potential for elucidating causative genes in complex disorders such as T1D. With at least 57 independent genetic variants contributing to overall risk, the need for experimental platforms to expedite validation of causal variants is paramount to the field of functional genomics. Before starting an iPSC project, a few considerations must be made: (1) What will be the source material for iPSC reprogramming (i.e., risk gene profile)? (2) Which of several available iPSC reprogramming methods will be utilized? and (3) What differentiation protocols are available for the cells of interest?

Each investigator must determine starting cell source and reprogramming method based on available cells and the ultimate research plan. Our group has found that $\mathrm{CD} 34^{+} \mathrm{HSC}$ isolated from peripheral blood can be efficiently reprogrammed into iPSCs using Sendai virus (Figure 5). This method has a few advantages over the use of PBMCs. First, $\mathrm{CD} 34^{+}$progenitor cells can be isolated from fresh, non-mobilized peripheral blood and expanded in vitro (111). Second, the efficiency to generate iPSCs is higher with this approach versus non-sorted PBMC. We have observed that as few as 2,000 isolated CD34 ${ }^{+}$HSCs yielded several iPSC colonies. Finally, the resultant iPSC will have native genetic configurations at both the TCR and immunoglobulin loci. However, CD $34^{+}$cells may not always be the best source of donor material. Where a re-arranged TCR with known antigen recognition is desired, $\mathrm{CD}^{+}$or $\mathrm{CD}^{+} \mathrm{T}$ cells from $\mathrm{T} 1 \mathrm{D}$ patients could be used. In addition, it is known that T-cell-derived iPSCs differentiate back into $\mathrm{T}$ cells more efficiently, putatively due to epigenetic memory of the lineage (73).

In addition to cell type, it is particularly important to know the T1D risk genotype(s) of donor materials. One initiative at the University of Florida Center for Cellular Reprogramming is building an iPSC resource for genomic medicine. Samples from 50 healthy donors ( 25 males/25 females) with genome-wide SNP typing performed using the ImmunoChip platform are being utilized to generate iPSC lines. The SNP library will include all known T1D risk variants making this cell library and others like it (e.g., the Helmsley Cellular Research Hub, cellhub.org) powerful tools for studying complex genetic traits. Such an iPSC library with SNP database will provide an extremely useful common platform for SNP validation studies in combination with conventional gene editing technologies (Figure 4). For example, starting from iPSC clones harboring heterozygous status for a particular SNP (Figure 4, Module A), an investigator can obtain SNP hemizygous clones through CRISPR/Cas9-mediated allele targeting. Using such clones, one can study the effect of SNP variations within isogenic conditions in a relatively short timeframe.

Reprogramming somatic cells into iPSC is no longer limited to the investigators who have developed various methods in their own labs. Since the initial discovery of the "Yamanaka Factors" in 2006 where four minimal genes (Oct3/4, Sox2, c-Myc, and Klf4) were identified as key iPSC reprogramming factors (112), numerous advancements in reprogramming gene delivery have been made: these include delivery of reprogramming genes as lentiviral transgenes, plasmid DNA, or messenger RNA. Each of these platforms has become commercially available in reprogramming kits so that most labs can reprogram iPSC from a variety of tissues. Our group has found most success with a Sendai virus reprogramming vector. This non-integrating and self-limiting murine parainfluenza virus delivers the four essential iPSC genes in a single polycistronic message (Figure 5B) (113-115). Regardless of the method used, iPSCs take on a highly pluripotent phenotype and can be used to differentiate numerous lineages.

We have highlighted earlier progress in differentiating iPSC into key immune, endocrine, and endothelial cell types. 


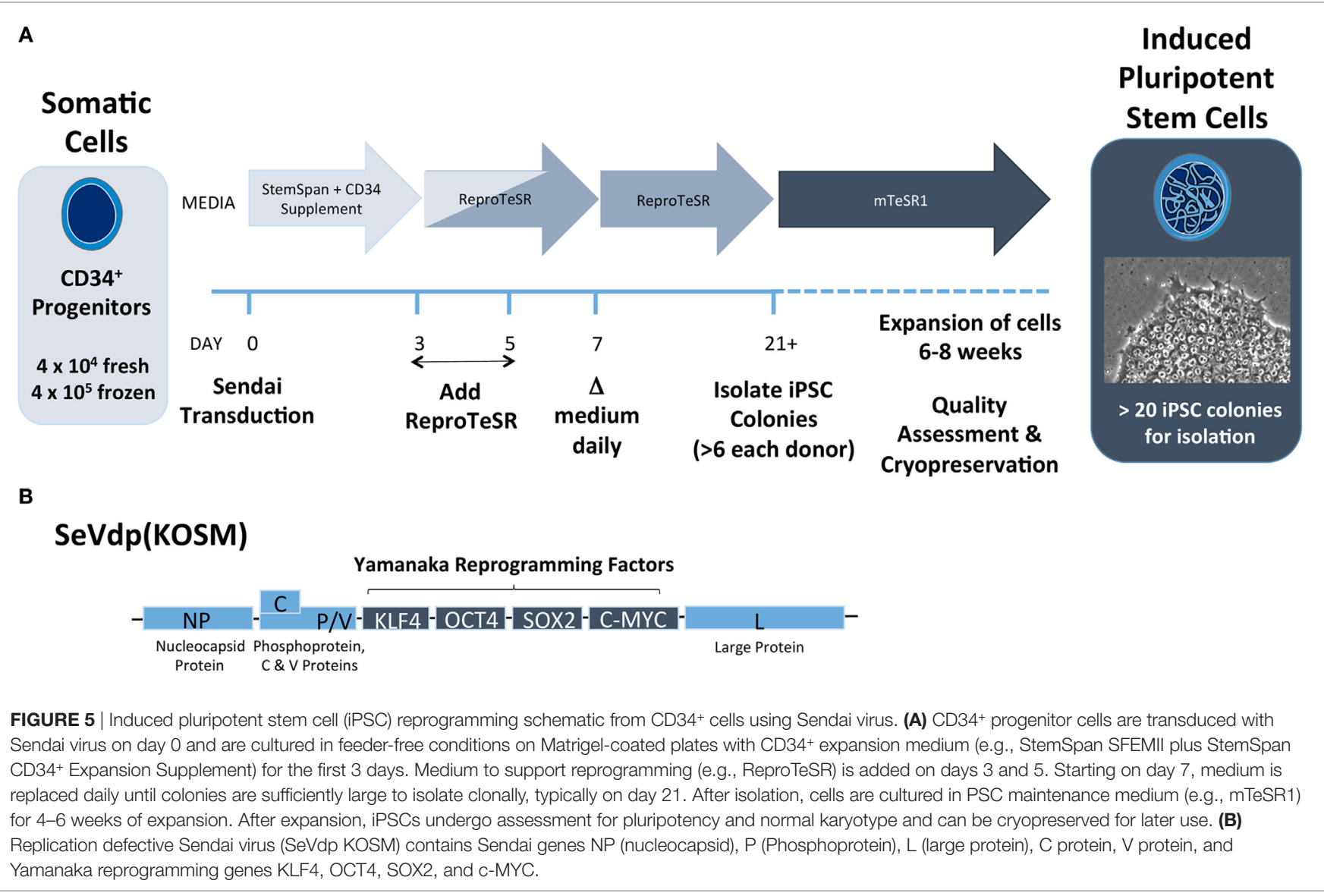

Without doubt, future applications of this approach will continue to expand as the community derives additional cell types from iPSC progenitor populations. The ability to switch between protective and susceptible variants and effectively turn genes on/off or up/down will allow the reductionist types of mechanistic studies previously only possible in gene knockout or transgenic animal models. One can certainly envision future models employing iPSC that layer increasingly complex admixtures of cells to recapitulate tissue micro-environments complete with multiple endocrine cell types, acinar tissues, microvasculature, and perhaps even innervation. We, along with others, are beginning to print living cells into liquid-like solid matrices allowing for exquisite control of cellular distribution in 3D space (116). The preliminary transcriptional profiles that have emerged from the transition from $2 \mathrm{D}$ culture in plastic wells to $3 \mathrm{D}$ cell culture have already suggested a distinct gene expression signature, more akin to that extracted from native tissues. Specific investigations using such $3 \mathrm{D}$ culture systems together with isogenic cellular models are needed to examine T1-IFN signaling with modulation of IFIH1 and TYK2 risk alleles as well as costimulatory pathways known to confer T1D risk (e.g., CD28/CTLA4 and CD226/TIGIT) (Table 1). Moreover, there will certainly be applications to reconstruct immune developmental niches to recapitulate key elements of hematopoietic development in the bone marrow, thymus, and secondary lymphoid organs. Such studies are expected to afford novel drug discovery through identification of new therapeutic targets.

The most obvious applications for stem cells in the T1D field reside in the ongoing need to replace the loss and functional inactivity of endogenous $\beta$ cell mass that precipitates glucose dysregulation [reviewed in Ref. (117)]. To date, this has been accomplished through both hES- and iPSC-derived insulinproducing $\beta$ cells. The capacity to model and recreate not only $\beta$ cells but also functional immune populations will allow the testing of therapies to close the translational loop and prevent recurrent auto- or allo-immune rejection of transplanted $\beta$ cells. Indeed, this might be accomplished by introducing genes to protect iPSCgenerated $\beta$ cells against apoptosis (e.g., GLIS3) (118) or to shield them from immunological attack, representing key objectives for iPSC-derived treatments in the regenerative medicine space.

Interventional trials to restore or preserve $\beta$ cells in T1D have largely been driven by individual investigator sponsored trials in the context of larger consortiums (e.g., TrialNet and the Immune Tolerance Network). These efforts have largely taken the form of repurposing clinically approved drugs from other diseases or have been based on preliminary studies generated in the NOD mouse model of T1D. While these efforts are beginning to demonstrate some transient preservation of C-peptide (the serum marker cosecreted in equimolar amounts with insulin), no current therapy has yet resulted in an FDA-approved intervention capable of demonstrating long-term efficacy (119-128). We propose that 
additional dose finding studies using human isogenic cellular systems to screen for desired mechanistic outcomes could potentially inform clinical trial agent selection and dosing.

From a patient perspective, the notion of equipoise limits experimental testing of many novel and/or high-risk combinatorial agents. By adopting isogenic cellular systems, those limitations could be mitigated by testing and optimizing prior to trial validations. Moreover, despite some demonstration of efficacy in preliminary trials (e.g., teplizumab, abatacept, alefacept, and ATG with or without G-CSF), no clear marker has emerged a priori that effectively predicts clinical responders or non-responders to any particular agent beyond basic cohort demographics of age, residual C-peptide, and disease duration (127-129). The use of isogenic cellular systems and personalized testing could facilitate drug selection and dose optimizations with clearly defined mechanistic readouts (e.g., phosphorylated-STAT5 response following low-dose IL-2) (130-133). Ultimately, the advent of genomic editing and isogenic cellular systems will not only enable a deeper understanding of disease pathogenesis but should also expedite the speed of discovery and clinical translation with the hope of both restoring $\beta$ cell mass and inducing durable antigenspecific immunological tolerance.

\section{CONCLUSION}

The emergence of genomic medicine has accelerated the rate of discovery with regard to the genetic basis of T1D. Multidimensional datasets now make it possible to overlay components of genetic variation, epigenetics, and transcriptional control of gene expression. Unfortunately, the vast number of associated SNPs, heterogeneity in human disease, and limits of clinical resources present a new set of challenges. There remains a paramount need to move beyond discovery of associated SNPs to a deeper understanding of causative variants to elucidate the molecular mechanisms and pathways of disease. The advent of iPSC technologies and precision gene editing now allows researchers to expedite the discovery and validation of these disease-associated variants.

Induced pluripotent stem cell technologies were initially met with great enthusiasm with the prospect of offering the capacity for regenerative medicine applications, including autologous $\beta$ cell replacement in T1D. While the robustness and efficiency of these approaches will continue to advance, the current

\section{REFERENCES}

1. Bluestone JA, Herold K, Eisenbarth G. Genetics, pathogenesis and clinical interventions in type 1 diabetes. Nature (2010) 464(7293):1293-300. doi: $10.1038 /$ nature 08933

2. Atkinson MA, Eisenbarth GS. Type 1 diabetes: new perspectives on disease pathogenesis and treatment. Lancet (2001) 358(9277):221-9. doi:10.1016/ S0140-6736(01)05415-0

3. Onengut-Gumuscu S, Chen WM, Burren O, Cooper NJ, Quinlan AR, Mychaleckyj JC, et al. Fine mapping of type 1 diabetes susceptibility loci and evidence for colocalization of causal variants with lymphoid gene enhancers. Nat Genet (2015) 47(4):381-6. doi:10.1038/ng.3245

4. Atkinson MA, Bluestone JA, Eisenbarth GS, Hebrok M, Herold KC, Accili D, et al. How does type 1 diabetes develop? The notion of homicide or beta-cell suicide revisited. Diabetes (2011) 60(5):1370-9. doi:10.2337/db10-1797 technologies exist to derive these cells, enabling researchers to build more powerful models of disease pathogenesis. Specifically, isogenic cellular systems now allow modeling of target $\beta$ cells, effector T-cell populations, and the innate and stromal components that interact with both the target organ and effector arms of the immune system. The capacity to rapidly derive these highly limited and rare populations at scale, all while targeting genomic loci in a high-throughput manner is expected to expedite functional genomics in a manner heretofore not observed. A detailed understanding of the mechanisms by which gene variants confer susceptibility or protection to disease will undoubtedly identify a number of key immunological lynchpins that can be therapeutically targeted in a rational approach to restore immune tolerance to $\beta$ cells in individuals with T1D.

\section{AUTHOR CONTRIBUTIONS}

MW and TB conceived the content and contributed to the writing and editing of the manuscript. KS and NT contributed to the writing and editing of the manuscript.

\section{ACKNOWLEDGMENTS}

The authors would like to thank the members of the University of Florida Diabetes Institute for insightful comments and discussions. The authors would like to thank Dr. Amanda Posgai for critical reading of the manuscript.

\section{FUNDING}

The content of this article is derived from research grants and support from the JDRF (CDA 2-2012-280 to TB) and ADA (ADA-1-17-JDF-048 to MW) and the Helmsley Charitable Trust. Content reviewed is supported by grants from the National Institutes of Health NIAID P01 AI42288, NIDDK HIRN 1UC4 DK104194-01, and R01 DK106191.

\section{SUPPLEMENTARY MATERIAL}

The Supplementary Material for this article can be found online at http://www.frontiersin.org/article/10.3389/fendo.2017.00276/ full\#supplementary-material.

5. Marson A, Housley WJ, Hafler DA. Genetic basis of autoimmunity. J Clin Invest (2015) 125(6):2234-41. doi:10.1172/JCI78086

6. Dendrou CA, Plagnol V, Fung E, Yang JH, Downes K, Cooper JD, et al. Cell-specific protein phenotypes for the autoimmune locus IL2RA using a genotype-selectable human bioresource. Nat Genet (2009) 41(9):1011-5. doi:10.1038/ng.434

7. Brehm MA, Cuthbert A, Yang C, Miller DM, Diiorio P, Laning J, et al. Parameters for establishing humanized mouse models to study human immunity: analysis of human hematopoietic stem cell engraftment in three immunodeficient strains of mice bearing the IL2rynull mutation. Clin Immunol (2010) 135(1):84-98. doi:10.1016/j.clim.2009. 12.008

8. Zschaler J, Schlorke D, Arnhold J. Differences in innate immune response between man and mouse. Crit Rev Immunol (2014) 34(5):433-54. doi:10.1615/ CritRevImmunol.2014011600 
9. Brehm MA, Powers AC, Shultz LD, Greiner DL. Advancing animal models of human type 1 diabetes by engraftment of functional human tissues in immunodeficient mice. Cold Spring Harb Perspect Med (2012) 2(5):a007757. doi:10.1101/cshperspect.a007757

10. Gianani R, Campbell-Thompson M, Sarkar SA, Wasserfall C, Pugliese A, Solis JM, et al. Dimorphic histopathology of long-standing childhood-onset diabetes. Diabetologia (2010) 53(4):690-8. doi:10.1007/s00125-0091642-y

11. Rowe PA, Campbell-Thompson ML, Schatz DA, Atkinson MA. The pancreas in human type 1 diabetes. Semin Immunopathol (2011) 33(1):29-43. doi:10.1007/s00281-010-0208-x

12. Coppieters KT, Dotta F, Amirian N, Campbell PD, Kay TW, Atkinson MA, et al. Demonstration of islet-autoreactive CD8 T cells in insulitic lesions from recent onset and long-term type 1 diabetes patients. J Exp Med (2012) 209(1):51-60. doi:10.1084/jem.20111187

13. Campbell-Thompson M, Fu A, Kaddis JS, Wasserfall C, Schatz DA, Pugliese A, et al. Insulitis and beta-cell mass in the natural history of type 1 diabetes. Diabetes (2016) 65(3):719-31. doi:10.2337/db15-0779

14. Rodriguez-Calvo T, Suwandi JS, Amirian N, Zapardiel-Gonzalo J, Anquetil F, Sabouri S, et al. Heterogeneity and lobularity of pancreatic pathology in type 1 diabetes during the prediabetic phase. J Histochem Cytochem (2015) 63(8):626-36. doi:10.1369/0022155415576543

15. Eisenbarth GS. Banting lecture 2009: an unfinished journey: molecular pathogenesis to prevention of type 1A diabetes. Diabetes (2010) 59(4):759-74. doi:10.2337/db09-1855

16. Barnett AH, Eff C, Leslie RD, Pyke DA. Diabetes in identical twins. A study of 200 pairs. Diabetologia (1981) 20(2):87-93. doi:10.1007/BF00262007

17. Redondo MJ, Yu L, Hawa M, Mackenzie T, Pyke DA, Eisenbarth GS, et al. Heterogeneity of type I diabetes: analysis of monozygotic twins in Great Britain and the United States. Diabetologia (2001) 44(3):354-62. doi:10.1007/ s001250051626

18. Laugesen E, Ostergaard JA, Leslie RD; Danish Diabetes Academy Workshop and Workshop Speakers. Latent autoimmune diabetes of the adult: current knowledge and uncertainty. Diabet Med (2015) 32(7):843-52. doi:10.1111/ dme. 12700

19. Redondo MJ, Jeffrey J, Fain PR, Eisenbarth GS, Orban T. Concordance for islet autoimmunity among monozygotic twins. N Engl J Med (2008) 359(26):2849-50. doi:10.1056/NEJMc0805398

20. Bradfield JP, Qu HQ, Wang K, Zhang H, Sleiman PM, Kim CE, et al. A genome-wide meta-analysis of six type 1 diabetes cohorts identifies multiple associated loci. PLoS Genet (2011) 7(9):e1002293. doi:10.1371/journal. pgen. 1002293

21. Barrett JC, Clayton DG, Concannon P, Akolkar B, Cooper JD, Erlich HA, et al. Genome-wide association study and meta-analysis find that over 40 loci affect risk of type 1 diabetes. Nat Genet (2009) 41(6):703-7. doi:10.1038/ ng.381

22. Wellcome Trust Case Control Consortium. Genome-wide association study of 14,000 cases of seven common diseases and 3,000 shared controls. Nature (2007) 447(7145):661-78. doi:10.1038/nature05911

23. Cooper JD, Smyth DJ, Smiles AM, Plagnol V, Walker NM, Allen JE, et al. Meta-analysis of genome-wide association study data identifies additional type 1 diabetes risk loci. Nat Genet (2008) 40(12):1399-401. doi:10.1038/ ng.249

24. Todd JA, Walker NM, Cooper JD, Smyth DJ, Downes K, Plagnol V, et al. Robust associations of four new chromosome regions from genome-wide analyses of type 1 diabetes. Nat Genet (2007) 39(7):857-64. doi:10.1038/ ng2068

25. Fortune MD, Guo H, Burren O, Schofield E, Walker NM, Ban M, et al. Statistical colocalization of genetic risk variants for related autoimmune diseases in the context of common controls. Nat Genet (2015) 47(7):839-46. doi:10.1038/ng.3330

26. Evangelou M, Smyth DJ, Fortune MD, Burren OS, Walker NM, Guo H, et al. A method for gene-based pathway analysis using genomewide association study summary statistics reveals nine new type 1 diabetes associations. Genet Epidemiol (2014) 38(8):661-70. doi:10.1002/gepi.21853

27. Sosenko JM, Skyler JS, Mahon J, Krischer JP, Beam CA, Boulware DC, et al. Validation of the diabetes prevention trial-type 1 risk score in the TrialNet natural history study. Diabetes Care (2011) 34(8):1785-7. doi:10.2337/ dc11-0641
28. Hummel S, Beyerlein A, Tamura R, Uusitalo U, Andren Aronsson C, Yang J, et al. First infant formula type and risk of islet autoimmunity in the environmental determinants of diabetes in the young (TEDDY) study. Diabetes Care (2017) 40(3):398-404. doi:10.2337/dc16-1624

29. Stene LC, Oikarinen S, Hyoty H, Barriga KJ, Norris JM, Klingensmith G, et al. Enterovirus infection and progression from islet autoimmunity to type 1 diabetes: the diabetes and autoimmunity study in the young (DAISY). Diabetes (2010) 59(12):3174-80. doi:10.2337/db10-0866

30. Ziegler AG, Meier-Stiegen F, Winkler C, Bonifacio E. Prospective evaluation of risk factors for the development of islet autoimmunity and type 1 diabetes during puberty - TEENDIAB: study design. Pediatr Diabetes (2012) 13(5):419-24. doi:10.1111/j.1399-5448.2011.00763.x

31. Achenbach P, Barker J, Bonifacio E. Modulating the natural history of type 1 diabetes in children at high genetic risk by mucosal insulin immunization. Curr Diab Rep (2008) 8(2):87-93. doi:10.1007/s11892-008-0017-y

32. Ferreira RC, Guo H, Coulson RM, Smyth DJ, Pekalski ML, Burren OS, et al. A type I interferon transcriptional signature precedes autoimmunity in children genetically at-risk of type 1 diabetes. Diabetes (2014) 63(7):2538-50. doi: $10.2337 / \mathrm{db} 13-1777$

33. Bottini N, Musumeci L, Alonso A, Rahmouni S, Nika K, Rostamkhani $\mathrm{M}$, et al. A functional variant of lymphoid tyrosine phosphatase is associated with type I diabetes. Nat Genet (2004) 36(4):337-8. doi:10.1038/ ng1323

34. Mi H, Muruganujan A, Thomas PD. PANTHER in 2013: modeling the evolution of gene function, and other gene attributes, in the context of phylogenetic trees. Nucleic Acids Res (2013) 41(Database issue):D377-86. doi:10.1093/nar/gks1118

35. Thomas PD, Campbell MJ, Kejariwal A, Mi H, Karlak B, Daverman R, et al. PANTHER: a library of protein families and subfamilies indexed by function. Genome Res (2003) 13(9):2129-41. doi:10.1101/gr.772403

36. Bersenev A, Wu C, Balcerek J, Jing J, Kundu M, Blobel GA, et al. Lnk constrains myeloproliferative diseases in mice. J Clin Invest (2010) 120(6):2058-69. doi:10.1172/JCI42032

37. Gery S, Cao Q, Gueller S, Xing H, Tefferi A, Koeffler HP. Lnk inhibits myeloproliferative disorder-associated JAK2 mutant, JAK2V617F. J Leukoc Biol (2009) 85(6):957-65. doi:10.1189/jlb.0908575

38. Yoshida K, Toki T, Okuno Y, Kanezaki R, Shiraishi Y, Sato-Otsubo A, et al. The landscape of somatic mutations in Down syndrome-related myeloid disorders. Nat Genet (2013) 45(11):1293-9. doi:10.1038/ng.2759

39. Westra HJ, Peters MJ, Esko T, Yaghootkar H, Schurmann C, Kettunen J, et al. Systematic identification of trans eQTLs as putative drivers of known disease associations. Nat Genet (2013) 45(10):1238-43. doi:10.1038/ng.2756

40. Gonzales AJ, Bowman JW, Fici GJ, Zhang M, Mann DW, Mitton-Fry M. Oclacitinib (APOQUEL $\left({ }^{\circledR}\right)$ ) is a novel Janus kinase inhibitor with activity against cytokines involved in allergy. J Vet Pharmacol Ther (2014) 37(4):31724. doi:10.1111/jvp.12101

41. Waters MJ, Brooks AJ. JAK2 activation by growth hormone and other cytokines. Biochem J (2015) 466(1):1-11. doi:10.1042/BJ20141293

42. Storling J, Pociot F. Type 1 diabetes candidate genes linked to pancreatic islet cell inflammation and beta-cell apoptosis. Genes (Basel) (2017) 8(2):E72. doi:10.3390/genes8020072

43. Grennan AK. Genevestigator. Facilitating web-based gene-expression analysis. Plant Physiol (2006) 141(4):1164-6. doi:10.1104/pp.104.900198

44. Ram R, Mehta M, Nguyen QT, Larma I, Boehm BO, Pociot F, et al. Systematic evaluation of genes and genetic variants associated with type 1 diabetes susceptibility. J Immunol (2016) 196(7):3043-53. doi:10.4049/ jimmunol.1502056

45. Anderson MS, Venanzi ES, Chen Z, Berzins SP, Benoist C, Mathis D. The cellular mechanism of Aire control of T cell tolerance. Immunity (2005) 23(2):227-39. doi:10.1016/j.immuni.2005.07.005

46. Fontenot JD, Rudensky AY. Molecular aspects of regulatory T cell development. Semin Immunol (2004) 16(2):73-80. doi:10.1016/j.smim.2003. 12.002

47. Husebye ES, Anderson MS. Autoimmune polyendocrine syndromes: clues to type 1 diabetes pathogenesis. Immunity (2010) 32(4):479-87. doi:10.1016/j. immuni.2010.03.016

48. Eisenbarth GS. Insulin autoimmunity: immunogenetics/immunopathogenesis of type 1A diabetes. Ann N Y Acad Sci (2003) 1005:109-18. doi:10.1196/ annals. 1288.012 
49. Kieback E, Hilgenberg E, Stervbo U, Lampropoulou V, Shen P, Bunse M, et al. Thymus-derived regulatory $\mathrm{T}$ cells are positively selected on natural self-antigen through cognate interactions of high functional avidity. Immunity (2016) 44(5):1114-26. doi:10.1016/j.immuni.2016.04.018

50. Pugliese A, Boulware D, Yu L, Babu S, Steck AK, Becker D, et al. HLADRB1 ${ }^{*}$ 15:01-DQA $1^{*} 01: 02-\mathrm{DQB} 1^{*} 06: 02$ haplotype protects autoantibody-positive relatives from type 1 diabetes throughout the stages of disease progression. Diabetes (2016) 65(4):1109-19. doi:10.2337/db15-1105

51. Sosinowski T, Eisenbarth GS. Type 1 diabetes: primary antigen/peptide/register/trimolecular complex. Immunol Res (2013) 55(1-3):270-6. doi:10.1007/ s12026-012-8367-6

52. van Lummel M, van Veelen PA, Zaldumbide A, de Ru A, Janssen GM, Moustakas AK, et al. Type 1 diabetes-associated HLA-DQ8 transdimer accommodates a unique peptide repertoire. JBiol Chem (2012) 287(12):9514-24. doi:10.1074/jbc.M111.313940

53. Bennett ST, Lucassen AM, Gough SC, Powell EE, Undlien DE, Pritchard LE, et al. Susceptibility to human type 1 diabetes at IDDM2 is determined by tandem repeat variation at the insulin gene minisatellite locus. Nat Genet (1995) 9(3):284-92. doi:10.1038/ng0395-284

54. Pugliese A, Zeller M, Fernandez A Jr, Zalcberg LJ, Bartlett RJ, Ricordi C, et al. The insulin gene is transcribed in the human thymus and transcription levels correlated with allelic variation at the INS VNTR-IDDM2 susceptibility locus for type 1 diabetes. Nat Genet (1997) 15(3):293-7. doi:10.1038/ng0397-293

55. Nakayama M, Abiru N, Moriyama H, Babaya N, Liu E, Miao D, et al. Prime role for an insulin epitope in the development of type 1 diabetes in NOD mice. Nature (2005) 435(7039):220-3. doi:10.1038/nature03523

56. Michels AW, Landry LG, McDaniel KA, Yu L, Campbell-Thompson M, Kwok WW, et al. Islet-derived CD4 T cells targeting proinsulin in human autoimmune diabetes. Diabetes (2017) 66(3):722-34. doi:10.2337/db16-1025

57. Mannering SI, Harrison LC, Williamson NA, Morris JS, Thearle DJ, Jensen $\mathrm{KP}$, et al. The insulin A-chain epitope recognized by human $\mathrm{T}$ cells is posttranslationally modified. J Exp Med (2005) 202(9):1191-7. doi:10.1084/ jem.20051251

58. Delong T, Wiles TA, Baker RL, Bradley B, Barbour G, Reisdorph R, et al. Pathogenic CD4 T cells in type 1 diabetes recognize epitopes formed by peptide fusion. Science (2016) 351(6274):711-4. doi:10.1126/science.aad2791

59. Wicker LS, Todd JA, Peterson LB. Genetic control of autoimmune diabetes in the NOD mouse. Annu Rev Immunol (1995) 13:179-200. doi:10.1146/ annurev.iy.13.040195.001143

60. Wicker LS, Miller BJ, Coker LZ, McNally SE, Scott S, Mullen Y, et al. Genetic control of diabetes and insulitis in the nonobese diabetic (NOD) mouse. J Exp Med (1987) 165(6):1639-54. doi:10.1084/jem.165.6.1639

61. Bingley PJ, Bonifacio E, Mueller PW. Diabetes antibody standardization program: first assay proficiency evaluation. Diabetes (2003) 52(5):1128-36. doi:10.2337/diabetes.52.5.1128

62. Torn C, Mueller PW, Schlosser M, Bonifacio E, Bingley PJ. Diabetes antibody standardization program: evaluation of assays for autoantibodies to glutamic acid decarboxylase and islet antigen-2. Diabetologia (2008) 51(5):846-52. doi:10.1007/s00125-008-0967-2

63. Schlosser M, Mueller PW, Torn C, Bonifacio E, Bingley PJ. Diabetes antibody standardization program: evaluation of assays for insulin autoantibodies. Diabetologia (2010) 53(12):2611-20. doi:10.1007/s00125-010-1915-5

64. Schlosser M, Mueller PW, Achenbach P, Lampasona V, Bingley PJ. Diabetes antibody standardization program: first evaluation of assays for autoantibodies to IA-2beta. Diabetes Care (2011) 34(11):2410-2. doi:10.2337/ dc11-1161

65. Lampasona V, Schlosser M, Mueller PW, Williams AJ, Wenzlau JM, Hutton JC, et al. Diabetes antibody standardization program: first proficiency evaluation of assays for autoantibodies to zinc transporter 8. Clin Chem (2011) 57(12):1693-702. doi:10.1373/clinchem.2011.170662

66. Wasserfall C, Montgomery E, Yu L, Michels A, Gianani R, Pugliese A, et al. Validation of a rapid type 1 diabetes autoantibody screening assay for community based screening of organ donors to identify subjects at increased risk for the disease. Clin Exp Immunol (2016) 185(1):33-41. doi:10.1111/ cei. 12797

67. Seay HR, Yusko E, Rothweiler SJ, Zhang L, Posgai AL, Campbell-Thompson $\mathrm{M}$, et al. Tissue distribution and clonal diversity of the T and B cell repertoire in type 1 diabetes. JCI Insight (2016) 1(20):e88242. doi:10.1172/jci. insight. 88242
68. Nepom GT, Buckner JH, Novak EJ, Reichstetter S, Reijonen H, Gebe J, et al. HLA class II tetramers: tools for direct analysis of antigen-specific CD4+ T cells. Arthritis Rheum (2002) 46(1):5-12. doi:10.1002/1529-0131(200201)46:1<5::AID-ART10063>3.0.CO;2-S

69. Brusko TM, Koya RC, Zhu S, Lee MR, Putnam AL, McClymont SA, et al. Human antigen-specific regulatory $\mathrm{T}$ cells generated by $\mathrm{T}$ cell receptor gene transfer. PLoS One (2010) 5(7):e11726. doi:10.1371/journal.pone. 0011726

70. Esensten JH, Bluestone JA, Lim WA. Engineering therapeutic T cells: from synthetic biology to clinical trials. Annu Rev Pathol (2017) 12:305-30. doi:10.1146/annurev-pathol-052016-100304

71. Newby BN, Brusko TM, Zou B, Atkinson MA, Clare-Salzler M, Mathews CE. Type 1 interferons potentiate human CD8+ T cell cytotoxicity through a STAT4 and granzyme B dependent pathway. Diabetes (2017):db170106. doi:10.2337/db17-0106

72. Yeh W-I, Seay HR, Newby B, Posgai AL, Moniz FB, Michels A, et al. Avidity and Bystander Suppressive Capacity of Human Regulatory T Cells Expressing De Novo Autoreactive T-Cell Receptors in Type 1 Diabetes. Front Immunol (2017) 8:1313. doi:10.3389/fimmu.2017.01313

73. Kaneko S. In vitro generation of antigen-specific $\mathrm{T}$ cells from induced pluripotent stem cells of antigen-specific T cell origin. Methods Mol Biol (2016) 1393:67-73. doi:10.1007/978-1-4939-3338-9_6

74. Vizcardo R, Masuda K, Yamada D, Ikawa T, Shimizu K, Fujii S, et al. Regeneration of human tumor antigen-specific $\mathrm{T}$ cells from iPSCs derived from mature CD8(+) T cells. Cell Stem Cell (2013) 12(1):31-6. doi:10.1016/j. stem.2012.12.006

75. Chang CW, Lai YS, Lamb LS Jr, Townes TM. Broad T-cell receptor repertoire in T-lymphocytes derived from human induced pluripotent stem cells. PLoS One (2014) 9(5):e97335. doi:10.1371/journal.pone.0097335

76. Maeda T, Nagano S, Ichise H, Kataoka K, Yamada D, Ogawa S, et al. Regeneration of CD8alphabeta $\mathrm{T}$ cells from T-cell-derived iPSC imparts potent tumor antigen-specific cytotoxicity. Cancer Res (2016) 76(23):683950. doi:10.1158/0008-5472.CAN-16-1149

77. Okabe M, Ito S, Nishio N, Tanaka Y, Isobe K. Thymic epithelial cells induced from pluripotent stem cells by a three-dimensional spheroid culture system regenerates functional T cells in nude mice. Cell Reprogram (2015) 17(5):368-75. doi:10.1089/cell.2015.0006

78. Marro BS, Ware BC, Zak J, de la Torre JC, Rosen H, Oldstone MB. Progression of type 1 diabetes from the prediabetic stage is controlled by interferon-alpha signaling. Proc Natl Acad Sci U S A (2017) 114(14):3708-13. doi:10.1073/ pnas. 1700878114

79. Pane JA, Fleming FE, Graham KL, Thomas HE, Kay TW, Coulson BS. Rotavirus acceleration of type 1 diabetes in non-obese diabetic mice depends on type I interferon signalling. Sci Rep (2016) 6:29697. doi:10.1038/srep29697

80. Ylipaasto P, Klingel K, Lindberg AM, Otonkoski T, Kandolf R, Hovi T, et al. Enterovirus infection in human pancreatic islet cells, islet tropism in vivo and receptor involvement in cultured islet beta cells. Diabetologia (2004) 47(2):225-39. doi:10.1007/s00125-003-1297-z

81. Gamble DR, Taylor KW. Seasonal incidence of diabetes mellitus. Br Med J (1969) 3(5671):631-3. doi:10.1136/bmj.3.5671.631

82. Schulte BM, Bakkers J, Lanke KH, Melchers WJ, Westerlaken C, Allebes W, et al. Detection of enterovirus RNA in peripheral blood mononuclear cells of type 1 diabetic patients beyond the stage of acute infection. Viral Immunol (2010) 23(1):99-104. doi:10.1089/vim.2009.0072

83. Gamble DR, Kinsley ML, FitzGerald MG, Bolton R, Taylor KW. Viral antibodies in diabetes mellitus. Br Med J (1969) 3(5671):627-30. doi:10.1136/ bmj.3.5671.627

84. Laitinen OH, Honkanen H, Pakkanen O, Oikarinen S, Hankaniemi MM, Huhtala $\mathrm{H}$, et al. Coxsackievirus $\mathrm{B} 1$ is associated with induction of beta-cell autoimmunity that portends type 1 diabetes. Diabetes (2014) 63(2):446-55. doi: $10.2337 / \mathrm{db} 13-0619$

85. Wang Y, Shaked I, Stanford SM, Zhou W, Curtsinger JM, Mikulski Z, et al. The autoimmunity-associated gene PTPN22 potentiates toll-like receptor-driven, type 1 interferon-dependent immunity. Immunity (2013) 39(1):111-22. doi:10.1016/j.immuni.2013.06.013

86. Wang Y, Ewart D, Crabtree JN, Yamamoto A, Baechler EC, Fazeli P, et al. PTPN22 variant R620W is associated with reduced toll-like receptor 7-induced type I interferon in systemic lupus erythematosus. Arthritis Rheumatol (2015) 67(9):2403-14. doi:10.1002/art.39211 
87. Ouyang P, Rakus K, van Beurden SJ, Westphal AH, Davison AJ, Gatherer D, et al. IL-10 encoded by viruses: a remarkable example of independent acquisition of a cellular gene by viruses and its subsequent evolution in the viral genome. J Gen Virol (2014) 95(Pt 2):245-62. doi:10.1099/vir.0.058966-0

88. Pennline KJ, Roque-Gaffney E, Monahan M. Recombinant human IL-10 prevents the onset of diabetes in the nonobese diabetic mouse. Clin Immunol Immunopathol (1994) 71(2):169-75. doi:10.1006/clin.1994.1068

89. Pop SM, Wong CP, He Q, Wang Y, Wallet MA, Goudy KS, et al. The type and frequency of immunoregulatory CD4+ T-cells govern the efficacy of antigen-specific immunotherapy in nonobese diabetic mice. Diabetes (2007) 56(5):1395-402. doi:10.2337/db06-0543

90. Goudy KS, Burkhardt BR, Wasserfall C, Song S, Campbell-Thompson ML, Brusko T, et al. Systemic overexpression of IL-10 induces CD4+CD25+ cell populations in vivo and ameliorates type 1 diabetes in nonobese diabetic mice in a dose-dependent fashion. J Immunol (2003) 171(5):2270-8. doi:10.4049/ jimmunol.171.5.2270

91. Marselli L, Dotta F, Piro S, Santangelo C, Masini M, Lupi R, et al. Th2 cytokines have a partial, direct protective effect on the function and survival of isolated human islets exposed to combined proinflammatory and Th1 cytokines. J Clin Endocrinol Metab (2001) 86(10):4974-8. doi:10.1210/jcem.86.10.7938

92. Calderon B, Suri A, Unanue ER. In CD4+ T-cell-induced diabetes, macrophages are the final effector cells that mediate islet beta-cell killing: studies from an acute model. Am J Pathol (2006) 169(6):2137-47. doi:10.2353/ ajpath.2006.060539

93. van Wilgenburg B, Browne C, Vowles J, Cowley SA. Efficient, long term production of monocyte-derived macrophages from human pluripotent stem cells under partly-defined and fully-defined conditions. PLoS One (2013) 8(8):e71098. doi:10.1371/journal.pone.0071098

94. Yanagimachi MD, Niwa A, Tanaka T, Honda-Ozaki F, Nishimoto S, Murata $\mathrm{Y}$, et al. Robust and highly-efficient differentiation of functional monocytic cells from human pluripotent stem cells under serum- and feeder cell-free conditions. PLoS One (2013) 8(4):e59243. doi:10.1371/journal.pone. 0059243

95. Richardson SJ, Rodriguez-Calvo T, Gerling IC, Mathews CE, Kaddis JS, Russell MA, et al. Islet cell hyperexpression of HLA class I antigens: a defining feature in type 1 diabetes. Diabetologia (2016) 59(11):2448-58. doi:10.1007/ s00125-016-4067-4

96. Jiang W, Shi Y, Zhao D, Chen S, Yong J, Zhang J, et al. In vitro derivation of functional insulin-producing cells from human embryonic stem cells. Cell Res (2007) 17(4):333-44. doi:10.1038/cr.2007.28

97. Shi Y. Generation of functional insulin-producing cells from human embryonic stem cells in vitro. Methods Mol Biol (2010) 636:79-85. doi:10.1007/978-1-60761-691-7_5

98. Bose B, Shenoy SP, Konda S, Wangikar P. Human embryonic stem cell differentiation into insulin secreting beta-cells for diabetes. Cell Biol Int (2012) 36(11):1013-20. doi:10.1042/CBI20120210

99. Zhang D, Jiang W, Liu M, Sui X, Yin X, Chen S, et al. Highly efficient differentiation of human ES cells and iPS cells into mature pancreatic insulin-producing cells. Cell Res (2009) 19(4):429-38. doi:10.1038/cr.2009.28

100. Thatava T, Nelson TJ, Edukulla R, Sakuma T, Ohmine S, Tonne JM, et al. Indolactam V/GLP-1-mediated differentiation of human iPS cells into glucose-responsive insulin-secreting progeny. Gene Ther (2011) 18(3):283-93. doi:10.1038/gt.2010.145

101. Kunisada Y, Tsubooka-Yamazoe N, Shoji M, Hosoya M. Small molecules induce efficient differentiation into insulin-producing cells from human induced pluripotent stem cells. Stem Cell Res (2012) 8(2):274-84. doi:10.1016/j.scr.2011.10.002

102. Toyoda T, Mae S, Tanaka H, Kondo Y, Funato M, Hosokawa Y, et al. Cell aggregation optimizes the differentiation of human ESCs and iPSCs into pancreatic bud-like progenitor cells. Stem Cell Res (2015) 14(2):185-97. doi:10.1016/j.scr.2015.01.007

103. Shahjalal HM, Shiraki N, Sakano D, Kikawa K, Ogaki S, Baba H, et al. Generation of insulin-producing beta-like cells from human iPS cells in a defined and completely xeno-free culture system. J Mol Cell Biol (2014) 6(5):394-408. doi:10.1093/jmcb/mju029

104. Kroon E, Martinson LA, Kadoya K, Bang AG, Kelly OG, Eliazer S, et al. Pancreatic endoderm derived from human embryonic stem cells generates glucose-responsive insulin-secreting cells in vivo. Nat Biotechnol (2008) 26(4):443-52. doi:10.1038/nbt1393
105. Rezania A, Bruin JE, Riedel MJ, Mojibian M, Asadi A, Xu J, et al. Maturation of human embryonic stem cell-derived pancreatic progenitors into functional islets capable of treating pre-existing diabetes in mice. Diabetes (2012) 61(8):2016-29. doi:10.2337/db11-1711

106. Szot GL, Yadav M, Lang J, Kroon E, Kerr J, Kadoya K, et al. Tolerance induction and reversal of diabetes in mice transplanted with human embryonic stem cell-derived pancreatic endoderm. Cell Stem Cell (2015) 16(2):148-57. doi:10.1016/j.stem.2014.12.001

107. Zhu S, Russ HA, Wang X, Zhang M, Ma T, Xu T, et al. Human pancreatic beta-like cells converted from fibroblasts. Nat Commun (2016) 7:10080. doi:10.1038/ncomms 10080

108. Peters EB. Endothelial progenitor cells for the vascularization of engineered tissues. Tissue Eng B Rev (2017). doi:10.1089/ten.teb.2017.0127

109. Kurokawa YK, Yin RT, Shang MR, Shirure VS, Moya ML, George SC. Human iPS-derived endothelial cells for 3D microphysiological systems. Tissue Eng C Methods (2017) 23(8):474-84. doi:10.1089/ten.tec.2017.0133

110. Wong WT, Huang NF, Botham CM, Sayed N, Cooke JP. Endothelial cells derived from nuclear reprogramming. Circ Res (2012) 111(10):1363-75. doi:10.1161/CIRCRESAHA.111.247213

111. Koizumi K, Sawada K, Yamaguchi M, Notoya A, Tarumi T, Takano H, et al In vitro expansion of $\mathrm{CD} 34+/ \mathrm{CD} 41+$ cells from human peripheral blood CD34+/CD41 - cells: role of cytokines for in vitro proliferation and differentiation of megakaryocytic progenitors. Exp Hematol (1998) 26(12):1140-7.

112. Takahashi K, Yamanaka S. Induction of pluripotent stem cells from mouse embryonic and adult fibroblast cultures by defined factors. Cell (2006) 126(4):663-76. doi:10.1016/j.cell.2006.07.024

113. Nakanishi M, Otsu M. Development of Sendai virus vectors and their potential applications in gene therapy and regenerative medicine. Curr Gene Ther (2012) 12(5):410-6. doi:10.2174/156652312802762518

114. Nishimura K, Segawa H, Goto T, Morishita M, Masago A, Takahashi H, et al. Persistent and stable gene expression by a cytoplasmic RNA replicon based on a noncytopathic variant Sendai virus. J Biol Chem (2007) 282(37):27383-91. doi:10.1074/jbc.M702028200

115. Nishimura K, Sano M, Ohtaka M, Furuta B, Umemura Y, Nakajima Y, et al. Development of defective and persistent Sendai virus vector: a unique gene delivery/expression system ideal for cell reprogramming. J Biol Chem (2011) 286(6):4760-71. doi:10.1074/jbc.M110.183780

116. Bhattacharjee T, Zehnder SM, Rowe KG, Jain S, Nixon RM, Sawyer WG, et al. Writing in the granular gel medium. Sci $A d v$ (2015) 1(8):e1500655. doi:10.1126/sciadv.1500655

117. Pipeleers D, Robert T, De Mesmaeker I, Ling Z. Concise review: markers for assessing human stem cell-derived implants as beta-cell replacement in type 1 diabetes. Stem Cells Transl Med (2016) 5(10):1338-44. doi:10.5966/ sctm.2015-0187

118. Nogueira TC, Paula FM, Villate O, Colli ML, Moura RF, Cunha DA, et al. GLIS3, a susceptibility gene for type 1 and type 2 diabetes, modulates pancreatic beta cell apoptosis via regulation of a splice variant of the $\mathrm{BH} 3-$ only protein Bim. PLoS Genet (2013) 9(5):e1003532. doi:10.1371/journal. pgen.1003532

119. Daifotis AG, Koenig S, Chatenoud L, Herold KC. Anti-CD3 clinical trials in type 1 diabetes mellitus. Clin Immunol (2013) 149(3):268-78. doi:10.1016/j. clim.2013.05.001

120. Hagopian W, Ferry RJ Jr, Sherry N, Carlin D, Bonvini E, Johnson S, et al. Teplizumab preserves $\mathrm{C}$-peptide in recent-onset type 1 diabetes: two-year results from the randomized, placebo-controlled Protege trial. Diabetes (2013) 62(11):3901-8. doi:10.2337/db13-0236

121. Herold KC, Gitelman SE, Ehlers MR, Gottlieb PA, Greenbaum CJ, Hagopian $\mathrm{W}$, et al. Teplizumab (anti-CD3 mAb) treatment preserves C-peptide responses in patients with new-onset type 1 diabetes in a randomized controlled trial: metabolic and immunologic features at baseline identify a subgroup of responders. Diabetes (2013) 62(11):3766-74. doi:10.2337/ db13-0345

122. Vudattu NK, Herold KC. Treatment of new onset type 1 diabetes with teplizumab: successes and pitfalls in development. Expert Opin Biol Ther (2014) 14(3):377-85. doi:10.1517/14712598.2014.881797

123. Orban T, Bundy B, Becker DJ, Dimeglio LA, Gitelman SE, Goland R, et al. Costimulation modulation with abatacept in patients with recent-onset type 1 diabetes: follow-up 1 year after cessation of treatment. Diabetes Care (2014) 37(4):1069-75. doi:10.2337/dc13-0604 
124. Pescovitz MD, Greenbaum CJ, Bundy B, Becker DJ, Gitelman SE, Goland $\mathrm{R}$, et al. B-lymphocyte depletion with rituximab and beta-cell function: two-year results. Diabetes Care (2014) 37(2):453-9. doi:10.2337/ dc13-0626

125. Rigby MR, Harris KM, Pinckney A, DiMeglio LA, Rendell MS, Felner EI, et al. Alefacept provides sustained clinical and immunological effects in new-onset type 1 diabetes patients. J Clin Invest (2015) 125(8):3285-96. doi:10.1172/JCI81722

126. Haller MJ, Gitelman SE, Gottlieb PA, Michels AW, Rosenthal SM, Shuster JJ, et al. Anti-thymocyte globulin/G-CSF treatment preserves $\beta$ cell function in patients with established type 1 diabetes. J Clin Invest (2015) 125(1):448-55. doi:10.1172/JCI78492

127. Haller MJ, Gitelman SE, Gottlieb PA, Michels AW, Perry DJ, Schultz AR, et al. Antithymocyte globulin plus G-CSF combination therapy leads to sustained immunomodulatory and metabolic effects in a subset of responders with established type 1 diabetes. Diabetes (2016) 65(12):3765-75. doi:10.2337/ db16-0823

128. Gitelman SE, Gottlieb PA, Felner EI, Willi SM, Fisher LK, Moran A, et al. Antithymocyte globulin therapy for patients with recent-onset type 1 diabetes: 2 year results of a randomised trial. Diabetologia (2016) 59(6):1153-61. doi:10.1007/s00125-016-3917-4

129. Tooley J, Vudattu N, Choi J, Cotsapas C, Devine L, Raddassi K, et al. Changes in T-cell subsets identify responders to FcR-nonbinding anti-CD3 $\mathrm{mAb}$ (teplizumab) in patients with type 1 diabetes. Eur J Immunol (2016) 46(1):230-41. doi:10.1002/eji.201545708
130. Bell CJ, Sun Y, Nowak UM, Clark J, Howlett S, Pekalski ML, et al. Sustained in vivo signaling by long-lived IL-2 induces prolonged increases of regulatory T cells. J Autoimmun (2015) 56:66-80. doi:10.1016/j.jaut.2014. 10.002

131. Klatzmann D, Abbas AK. The promise of low-dose interleukin-2 therapy for autoimmune and inflammatory diseases. Nat Rev Immunol (2015) 15(5):283-94. doi:10.1038/nri3823

132. Hulme MA, Wasserfall $\mathrm{CH}$, Atkinson MA, Brusko TM. Central role for interleukin-2 in type 1 diabetes. Diabetes (2012) 61(1):14-22. doi:10.2337/ db11-1213

133. Long SA, Rieck M, Sanda S, Bollyky JB, Samuels PL, Goland R, et al. Rapamycin/IL-2 combination therapy in patients with type 1 diabetes augments Tregs yet transiently impairs beta-cell function. Diabetes (2012) 61(9):2340-8. doi:10.2337/db12-0049

Conflict of Interest Statement: The authors declare that the research was conducted in the absence of any commercial or financial relationships that could be construed as a potential conflict of interest.

Copyright (c) 2017 Wallet, Santostefano, Terada and Brusko. This is an open-access article distributed under the terms of the Creative Commons Attribution License (CC $B Y)$. The use, distribution or reproduction in other forums is permitted, provided the original author(s) or licensor are credited and that the original publication in this journal is cited, in accordance with accepted academic practice. No use, distribution or reproduction is permitted which does not comply with these terms. 